\title{
Research and Experimental Verification on Coupling Mechanical Characteristics of Surrounding Rock of Hydraulic Support Group in Comprehensive Working Face
}

\section{Kun Zhang}

Shandong University of Science and Technology

Xian Chi

Shandong University of Science and Technology

\section{Ying Ma}

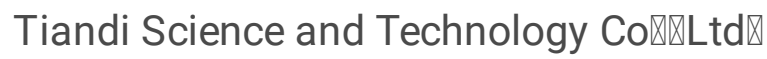

\section{Xia Li}

Shandong University of Science and Technology

\section{Long Feng ( $\nabla$ fenglong126224@126.com )}

Shandong University of Science and Technology

Da Li

Liaoning Technical University

Jun Xu

Tiandi Science and Technology CoهַLtd囚

\section{Yue Chen}

Liaoning Technical University

Sheng Zhang

Tiandi Science and Technology CoهַLtd】

\section{Song Huang}

Shandong University of Science and Technology

\section{Research Article}

Keywords: hydraulic support group, mechanical properties of roof, ideal support strength, variable parameter calculation, underground experiment

Posted Date: February 1st, 2021

DOl: https://doi.org/10.21203/rs.3.rs-145463/v1 
License: (c) (i) This work is licensed under a Creative Commons Attribution 4.0 International License. Read Full License 


\section{Research and experimental verification on coupling mechanical characteristics of surrounding rock of hydraulic support group in comprehensive working face}

Kun Zhang ${ }^{1,3}$, Zengxian $\mathrm{Chi}^{1}{ }^{1}$, Ying Ma ${ }^{2}$, Yu-xia $\mathrm{Li}^{1}$, Long Feng ${ }^{1}$, Teng-da $\mathrm{Li}^{3}$, Ya-jun Xu ${ }^{2}$, Hong-yue Chen ${ }^{3}$, De-sheng Zhang ${ }^{2}$, Liang-song Huang ${ }^{1}$

${ }^{1}$ Shandong Provincial Key Laboratory of Robotics and Intelligent Technology, Shandong University of Science and Technology, Qianwangang Road 579, Qingdao, Shandong Province, 266590, China

${ }^{2}$ Coal Mining Technology Department, Tiandi Science and Technology Co. , Ltd. , Qingniangou Road 5, Beijing, 100013, China

${ }^{3}$ College of Mechanical Engineering, Liaoning Technical University, Yulong Road 88, Fuxin City, Liaoning Province, 123000, China.

Corresponding author: Long Feng(e-mail: fenglong126224@126.com ).

\section{Abstract:}

The hydraulic support group and the surrounding rock in fully mechanized mining faces often do not exist in isolation; rather, they compose in a mutually coupled system. Research on the mechanical characteristics of roofs under the support of group supports can lay a foundation for the determination of the ideal support strength of group support equipment. This paper establishes a coupled mechanical model of the surrounding rock of hydraulic support groups in a fully mechanized mining face. Through variable parameter calculations, the influence of different roof elastic moduli, mining heights, working face lengths, end face distances, support stiffnesses, coal wall stiffnesses and direct roof thicknesses on roof deformation is analyzed, and the corresponding ideal support strength of a hydraulic support is given. The results show that: the deformation of the roof and the ideal support strength of the hydraulic support group decrease as the elastic modulus of the roof increase; the deformation amount of the roof and the ideal support strength of the hydraulic support group increase as the mining height increases; the deformation amount of the roof and the ideal support strength of the hydraulic support group increase as the working face length increases; the deformation amount of the roof and the hydraulic support group also increase. The results also show that the ideal support strength of the support group decreases as the face distance of the top beam end increases; the deformation of the roof decreases significantly as the equivalent stiffness of the hydraulic support group increases, but the ideal support strength of the hydraulic support group increases significantly; the deformation amount of the roof and the ideal support strength of the hydraulic support group decrease significantly as the equivalent stiffness of the coal wall increases; and the deformation amount of the roof and the hydraulic support are significantly reduced. The ideal support strength of the support group decreases as the thickness of the direct roof increases, especially in the middle of the working face. Finally, by setting the ideal support strength in the 12401 
working face of the Shangwan Coal Mine of Shendong Group, the accuracy of the calculation results is verified by the multisensor measurement method. The research results provide theoretical support for the development of coal resources for deep mining and intelligent directions on Earth.

Key words: hydraulic support group; mechanical properties of roof; ideal support strength; variable parameter calculation; underground experiment

\section{Introduction}

Hydraulic supports are an important type of support equipment in the support systems of fully mechanized mining faces. The ideal support strength of a hydraulic support adapted to roof deformation is the focus of attention at the fully mechanized mining face, 'oversupport' and 'undersupport', in terms of the stability of the entire work surface. The roof and hydraulic support compose a mutually coupled system; therefore, predictions of the roof deformation and support strength should consider the coupling effects of the supporting equipment and the surrounding rock.

With in-depth research on hydraulic supports, many experts have conducted research on the interaction between hydraulic supports and the surround rock. Qian et al. [1] studied the force characteristics of comprehensive mining face hydraulic supports; for the first time, the hydraulic support and the surrounding rock were regarded as a whole, and the interaction between them was deeply theoretically analyzed to reveal the coupling relationship between the work resistance of the support and the subsidence of the roof; Liu et al. [2] simplified the direct roof of the working face into a deformable medium, analyzed the deformation and failure characteristics of this medium based on the carrying capacity of the direct roof, divided the roof into a nonbearing area, a bearing area and a weak bearing area and proposed the concept and calculation method for the direct roof stiffness of a working face; Wu et al. [3] discussed the adaptability of hydraulic supports to the surrounding rock, basis of the influence law of the surrounding rock pressure on the working face support and surrounding rock; Wu et al. [4-6] conducted similar tests, studied the law of roof movement in fully mechanized mining faces with large heights, researched the interaction between the pressure in front of the work and roof cutting and revealed the coupling relationship between the advanced support and the pressure of roof cutting. Wang et al. [7] analyzed the law of top coal crushing in a fully mechanized mining face with a large height and the breaking law of direct and basic roofs to reveal the reason why the mining pressure appears to be severe at mining faces with large heights. Subsequently, Wang et al. [8] further used the mechanical model of a "voussoir beam", proposed a detailed classification of the roof load acting on the hydraulic support and studied the coupling relationship between the support and the surrounding rock. Based on the proposed strength coupling between the hydraulic support and the surrounding rock, the stiffness coupling and the stability coupling, they further established an adaptability evaluation model based on the comprehensive index of the adaptability of the support and the surrounding rock and studied the acquisition method and evaluation process of adaptability evaluation indicators.

Wang et al. [9] used the plate and shell theory and simplified the basic roof to a 
thin plate. On the basis of elasticity, a mechanical model of the first breaking of the basic roof was established. They performed an in-depth studied of the influence law of the elastic foundation coefficient, roof stiffness and span on basic roof breaking and, revealed the mechanism of basic top breaking under different parameters; Xie et al. [10] used the finite difference method and researched the influence law of the interval, elastic foundation stiffness coefficient and basic roof mechanical parameters on first breaking of the roof. Then, the roof breakage of the goaf side [11] and backfill for coal mining [12] were thoroughly studied. $\mathrm{Xu}$ et al. [13-15] simplified the hydraulic support into an elastic base and simplified the roof to a rock beam. A one-dimensional mechanical model of the support roof was established. According to the model, they obtained the stress field of the hydraulic support, which provides a foundation for a reasonable determination of the support strength.

Hydraulic supports in a fully mechanized mining face are not isolated; they form a coupled system with the roof bottom plate and gangue. In the literature, the support strength of the hydraulic support in a fully mechanized mining face with a high mining height is typically analyzed separately; in other words, the coupling characteristics of the support and the surrounding rock are ignored. As a result, the support strength is often inadequate to effectively meet the support requirements, causing the support efficiency to be low. Therefore, it is very important to analyze the coupled mechanical characteristics of the surrounding rock of the hydraulic support group and lay a foundation for the determination of the ideal support strength.

Based on the above, this paper considers the restraint effect of coal walls and roadways on the roof. The coupled mechanical model of the surrounding rock of the hydraulic support group was established and solved. Subsequently, the influence of different parameters on the coupled mechanical system of hydraulic support groups was researched. The law of interaction between the bracket and the roof provides a foundation for the determination of the ideal supporting strength of hydraulic supports under different working conditions.

\section{Establishment of the Coupled Mechanical Model of the Support Group and the Surrounding Rock}

\subsection{Description of the Coupled Mechanical Model}

A fully mechanized mining face is an interaction system mainly composed of hydraulic support-roof-coal walls, which do not exist in isolation and influence one another. In actual engineering, to determine the group support strength of hydraulic supports, the influence of interaction factors is often ignored. Therefore, the given support strength cannot adapt to the deformation of the roof; as a result, the supporting effect of the fully mechanized mining face is not up to expectations. This article takes into consideration the restraint effects of coal walls and roadways to form an excellent coupled mechanical model of the surrounding rock of the working face support group.

According to actual engineering, the roof is simplified to a flat plate, the cutting hole edge of the plate is free and the other three ends are constrained by coal walls and roadways. Meanwhile, the hydraulic support group is simplified as a surface 
elastic foundation. The specific schematic diagram is shown in Figure 1. The $\mathrm{x}$ direction is the length of the working surface, the y direction is the forward direction of the working face, and the $\mathrm{z}$ direction is the thickness of the roof. The $\mathrm{AB}$ side of the roof is restrained by the coal wall, and the $\mathrm{AD}$ and $\mathrm{BC}$ sides are constrained by the roadway. L1 is the length of the fully mechanized mining face, and L2 is the length of the forward direction.
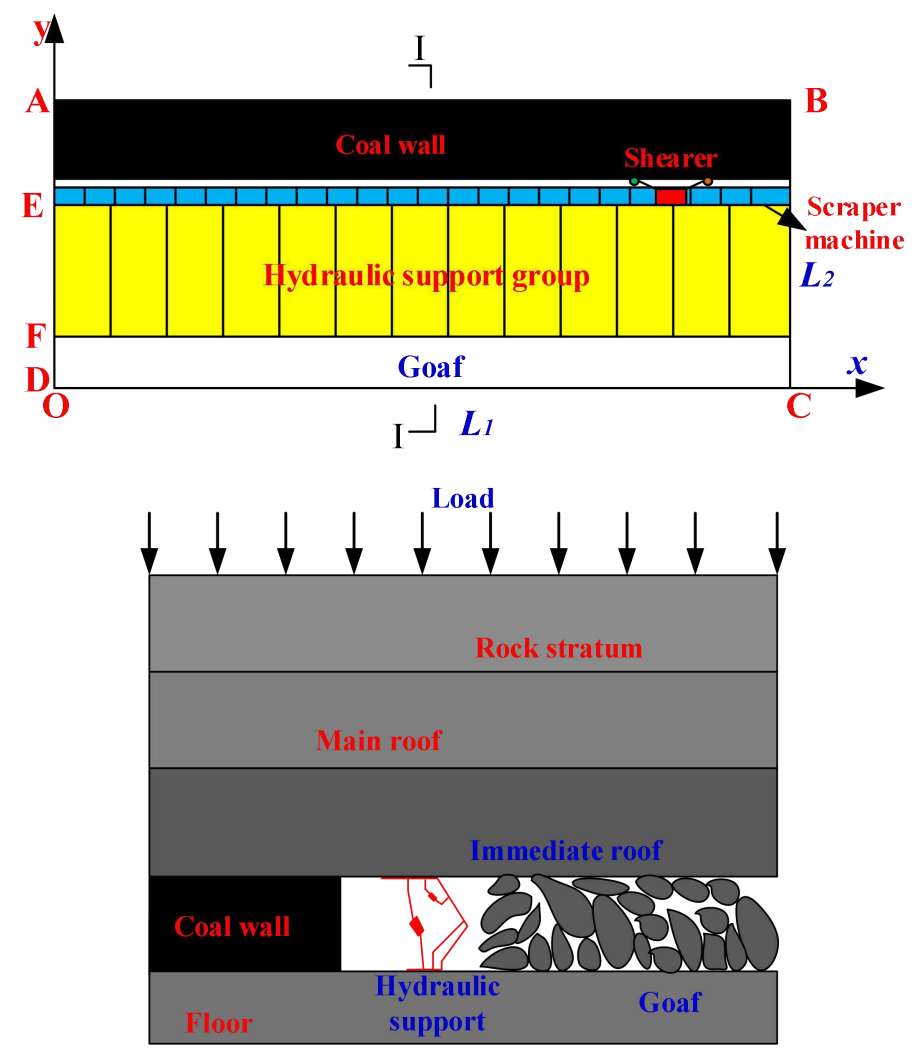

Fig. 1. Support group surrounding the coupled rock system in a fully mechanized mining face

\subsection{Description the Governing Equations}

Due to the large thickness of the roof of the working face, plate theory is adopted here. Assume that the top board meets the following conditions: (1) Before roof deformation, a straight line perpendicular to the midplane is still straight after deformation; (2) the normal stress on each surface parallel to the midplane is smaller than the other stresses; (3) and in the roof, there is no displacement of each point in the plane parallel to the middle plane [16].

According to the theory for a plate of a moderate thickness, the displacement of the roof in the $\mathrm{x}, \mathrm{y}$ and $\mathrm{z}$ directions can be expressed as:

$$
\begin{aligned}
& u=z \varphi_{x}(x, y) \\
& v=z \varphi_{y}(x, y) \\
& w=w(x, y)
\end{aligned}
$$

where $\varphi_{x}$ and $\varphi_{y}$ are the rotation angles of the roof about the $\mathrm{y}$ axis and the $\mathrm{x}$ axis, respectively, and $w$ is the displacement in the $\mathrm{z}$ direction. 
According to the displacement strain relationship, the strain expression of the roof is:

$$
\begin{gathered}
\varepsilon_{x}=z \frac{\partial \varphi_{x}}{\partial x}, \varepsilon_{y}=z \frac{\partial \varphi_{y}}{\partial y}, \varepsilon_{z}=0 \\
\gamma_{x y}=z\left(\frac{\partial \varphi_{x}}{\partial y}+\frac{\partial \varphi_{y}}{\partial x}\right), \gamma_{x z}=\varphi_{x}+\frac{\partial w}{\partial x}, \gamma_{y z}=\varphi_{y}+\frac{\partial w}{\partial y}
\end{gathered}
$$

The stress in each direction of the roof can be further expressed as:

$$
\left\{\begin{array}{l}
\sigma_{x} \\
\sigma_{y} \\
\tau_{y z} \\
\tau_{x z} \\
\tau_{x y}
\end{array}\right\}=\left[\begin{array}{ccccc}
Q_{11} & Q_{12} & 0 & 0 & 0 \\
Q_{12} & Q_{11} & 0 & 0 & 0 \\
0 & 0 & k Q_{66} & 0 & 0 \\
0 & 0 & 0 & k Q_{66} & 0 \\
0 & 0 & 0 & 0 & Q_{66}
\end{array}\right]\left\{\begin{array}{l}
\varepsilon_{x} \\
\varepsilon_{y} \\
\gamma_{y z} \\
\gamma_{x z} \\
\gamma_{x y}
\end{array}\right\}
$$

where $\mathrm{k}$ is the shear correction factor, which is defined as 5/6. Qij $(\mathrm{i}, \mathrm{j}=1,2,6)$ is the elastic parameter of the roof and can be further expressed as

$$
Q_{11}=\frac{E}{1-v^{2}}, Q_{12}=\frac{v E}{1-v^{2}}, Q_{66}=G
$$

where, $E, G$ and $v$ are the elastic modules, shear modulus and Poisson's ratio of the roof, respectively. The shear modulus and elastic modulus have the following relationship: $G=E / 2(1+v)$.

The energy stored in the hydraulic support group is

$$
U_{e}=\frac{1}{2} \int_{S} K_{h s} w^{2} d S
$$

where $K_{h s}$ is the equivalent stiffness of the hydraulic support, and $S$ is the supporting area of the hydraulic support group.

The strain energy expression of the roof is [16]:

$$
U=\frac{1}{2} \int_{0}^{L_{1}} \int_{0}^{L_{2}} \int_{-h / 2}^{h / 2}\left[\begin{array}{l}
\sigma_{x} \varepsilon_{x}+\sigma_{y} \varepsilon_{y}+\tau_{x y} \gamma_{x y} \\
+\tau_{x z} \gamma_{x z}+\tau_{y z} \gamma_{y z}
\end{array}\right] d x d y d z+U_{e}
$$

The penalty function term is introduction into the energy term [17]:

$$
\begin{aligned}
& U_{s}=\frac{1}{2} \int_{0}^{L_{2}}\left\{\begin{array}{l}
{\left[K_{w x 0} w^{2}+K_{x x 0} \varphi_{x}^{2}+K_{y x 0} \varphi_{y}^{2}\right]_{x=0}} \\
+\left[K_{w x L_{1}} w^{2}+K_{x x L_{1}} \varphi_{x}^{2}+K_{y x L_{1}} \varphi_{y}^{2}\right]_{x=L_{1}}
\end{array}\right\} d y \\
& +\frac{1}{2} \int_{0}^{L_{1}}\left\{\begin{array}{l}
{\left[K_{w y 0} w^{2}+K_{x y 0} \varphi_{x}^{2}+K_{y y 0} \varphi_{y}^{2}\right]_{y=0}} \\
+\left[K_{w y L_{2}} w^{2}+K_{x y L_{2}} \varphi_{x}^{2}+K_{y y L_{2}} \varphi_{y}^{2}\right]_{y=L_{2}}
\end{array}\right\} d x
\end{aligned}
$$

On the roof, the overburden pressure on the system is:

$$
W=\int_{0}^{L_{1}} \int_{0}^{L_{2}} P_{z} w d x d y
$$

where $P_{z}$ is the pressure acting on the top of the roof. According to the research, the 
load acting on the roof is estimated based on 4.6 9.0 times the weight of the mining-height of the rock pillar [14], Assuming the thickness of the direct roof is $h_{\mathrm{z}}$, mining-height is $h_{\mathrm{c}}$, the external load pressure acting on the roof is $\gamma\left(9 h_{c}-h_{z}\right)$, where, $\gamma$ is the bulk density of the overlying rock.

According to the Ritz method, the displacement of the roof is represented by a set of complete basis functions, and the Chebyshev polynomial of the first kind is chosen as the basis function. The displacement of the basic roof can be expressed as:

$$
\begin{aligned}
& \varphi_{x}(x, y)=\sum_{m=0}^{M} \sum_{n=0}^{N} A_{m n} \Phi_{m}(x) \Psi_{n}(y) \\
& \varphi_{y}(x, y)=\sum_{m=0}^{M} \sum_{n=0}^{N} B_{m n} \Phi_{m}(x) \Psi_{n}(y) \\
& w(x, y)=\sum_{m=0}^{M} \sum_{n=0}^{N} C_{m n} \Phi_{m}(x) \Psi_{n}(y)
\end{aligned}
$$

The Chebyshev polynomial of the first kind is given as follow [17]:

$$
\begin{aligned}
& \Phi_{0}(\xi)=1, \Phi_{1}(\xi)=\xi \\
& \Phi_{m+1}(\xi)=2 \xi \Phi_{m}(\xi)-\Phi_{m-1}(\xi), m \geq 2
\end{aligned}
$$

According to the Hamilton principle [17]:

$$
\delta\left(-U-U_{s}+W\right)=0
$$

Substituting formulas (6) (11) into formula (11) yields

$$
\left|\begin{array}{lll}
\mathbf{K}_{\varphi_{x} \varphi_{x}} & \mathbf{K}_{\varphi_{x} \varphi_{y}} & \mathbf{K}_{\varphi_{x} w} \\
\mathbf{K}_{\varphi_{y} \varphi_{x}} & \mathbf{K}_{\varphi_{y} \varphi_{y}} & \mathbf{K}_{\varphi_{y} w} \\
\mathbf{K}_{w \varphi_{x}} & \mathbf{K}_{w \varphi_{y}} & \mathbf{K}_{w w}
\end{array}\right|\left\{\begin{array}{l}
\mathbf{q}_{1} \\
\mathbf{q}_{2} \\
\mathbf{q}_{3}
\end{array}\right\}=\left\{\begin{array}{c}
\mathbf{0} \\
\mathbf{0} \\
\mathbf{H}^{\mathrm{T}} P_{z}
\end{array}\right\}
$$

By solving the above formula, we obtain the displacement of the basic top under an external load. According to the displacement, to further obtain the stress and bending moment of the roof, the expression is as follows [17]:

$$
\begin{aligned}
& M_{x}=D\left[\frac{\partial \varphi_{x}}{\partial x}+v \frac{\partial \varphi_{y}}{\partial y}\right], S_{x}=12 \frac{M_{x} z}{h^{3}} \\
& M_{y}=D\left[\frac{\partial \varphi_{y}}{\partial y}+v \frac{\partial \varphi_{x}}{\partial x}\right], S_{y}=12 \frac{M_{y} z}{h^{3}} \\
& M_{x y}=\frac{D(1-v)}{2}\left[\frac{\partial \varphi_{x}}{\partial y}+\frac{\partial \varphi_{y}}{\partial x}\right], S_{x y}=12 \frac{M_{x y} z}{h^{3}}
\end{aligned}
$$

where $D=E h^{3} / 12\left(1-v^{2}\right)$.

Furthermore, the expressions of the principal stress and the principal bending moment of the roof can be obtained as follows [17]: 


$$
\begin{aligned}
& M_{1}=\frac{M_{x}+M_{y}}{2}+\sqrt{\left(\frac{M_{x}-M_{y}}{2}\right)^{2}+M_{x y}^{2}} \\
& M_{3}=\frac{M_{x}+M_{y}}{2}-\sqrt{\left(\frac{M_{x}-M_{y}}{2}\right)^{2}+M_{x y}^{2}} \\
& S_{1}=\frac{S_{x}+S_{y}}{2}+\sqrt{\left(\frac{S_{x}-S_{y}}{2}\right)^{2}+S_{x y}^{2}} \\
& S_{3}=\frac{S_{x}+S_{y}}{2}-\sqrt{\left(\frac{S_{x}-S_{y}}{2}\right)^{2}+S_{x y}^{2}}
\end{aligned}
$$

\section{Calculation and discussion}

\subsection{Numerical examples}

This article takes the 12401 face of the Shangwan Coal Mine of the Shendong Group as the research background to study the coupling characteristics between the support group and the surrounding rock. According to the geological conditions of the working face, the roof length is $240 \mathrm{~m}$, the width is $110 \mathrm{~m}$, the thickness is $6 \mathrm{~m}$, the elastic modulus is $30 \mathrm{GPa}$ and Poisson's ratio is 0.27 . The bulk density of the overburden rock [18] is $24.2 \mathrm{kN} / \mathrm{m}^{3}$. The thickness of the direct roof is $9.3 \mathrm{~m}$, and the mining height is $8.8 \mathrm{~m}$. Assuming that one end of the roof is constrained by the coal wall, the other two vertical sides are constrained by the roadway. The roof is on the coal wall, and the equivalent stiffness value of the roadway [9] is $3 \mathrm{e} 9 \mathrm{~N} / \mathrm{m}^{2}$. The length of the top beam of the hydraulic support for the large mining height is $6.3 \mathrm{~m}$, the center distance is $2.2 \mathrm{~m}$, the end face distance is $0.7 \mathrm{~m}$ and the equivalent stiffness $[15]$ is $40 \mathrm{MN} / \mathrm{m}^{3}$.

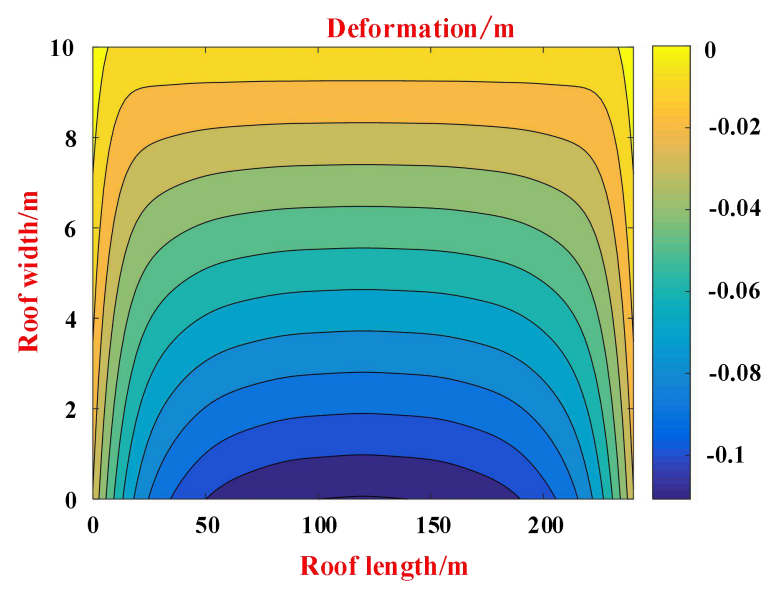

Fig. 2. The contour of the deflection of the roof

The deformation cloud image of the roof was obtained by calculation, as shown in Figure 2. Obviously, because the roof is supported on the coal wall and the roadway, the amount of deformation is small, and the roof has the largest displacement close to the cutting hole (exposed end), which is consistent with the actual fully mechanized mining face. Further observations of the bending moment and stress information of the roof are shown in Figure 3. In this example, the length of the working surface is much larger than the size of the forward direction of the support, and the maximum bending moment and stress of the roof appear at the short side of the roof. This means 
that the roof may crack first from the short side and then expand step by step until the entire roof collapses.

Further calculations reveal the deformation of the roof directly above the column of the hydraulic support group, as shown in Figure 4. Under this condition, the deformation of the roof is small at both ends and large in the middle. Figure 5 shows the strength curve of the group support of the hydraulic support adapted to roof deformation (the ideal support strength of the hydraulic support). The strength curve is consistent with the change trend of roof deformation. The support strength of the hydraulic support is also small at both ends and large in the middle. The strength curve also complies with the law of monitoring in the mine in which the support strength in the middle of the working face is high and the support strength at both ends is small. The effectiveness of this model was verified. In addition, the deformation of the roof and the hydraulic support group in the middle part of the working face change quite smoothly. This change means that when the support is actually supporting the roof in the length direction of the working face, attention should be paid to the reasonable determination of the support strength of the hydraulic support.
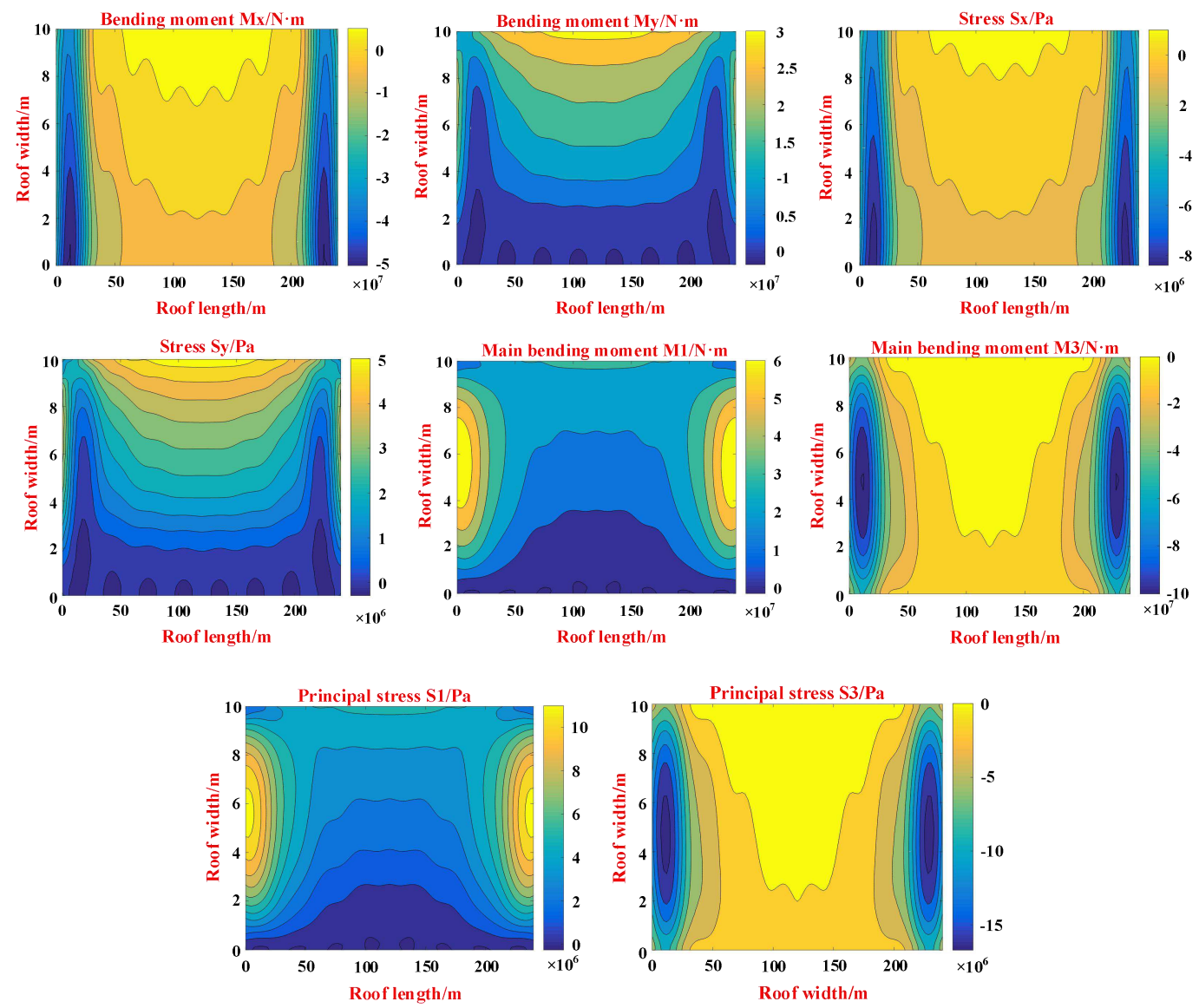

Fig. 3. Contour of the moment and stress of the roof 


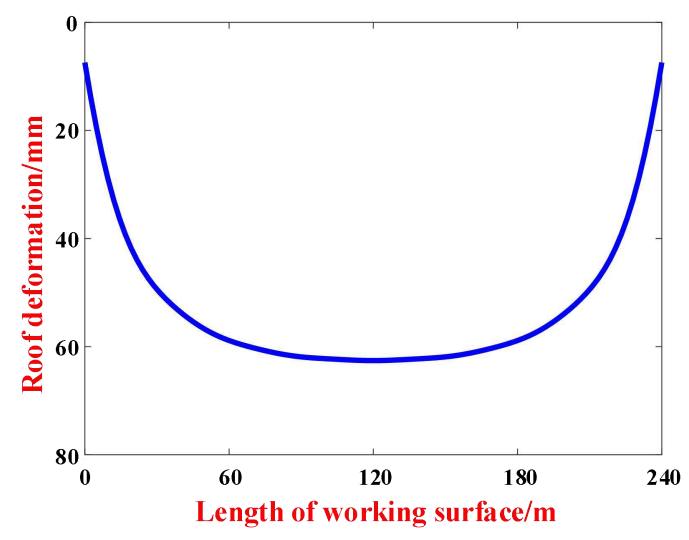

Fig. 4. The deflection of the roof above the hydraulic supports

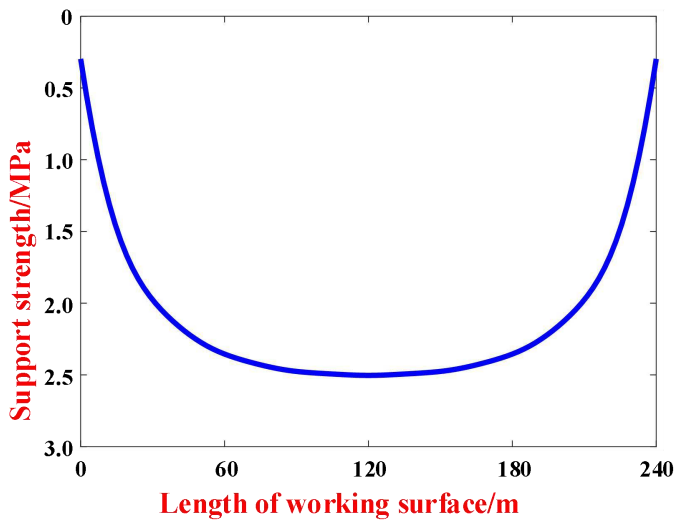

Fig. 5. The support strength of the hydraulic supports

\subsection{Variable parameter calculation}

In the actual supporting process, the related parameters of the surrounding rock and the degree of fracture of the section have a greater impact on the coupling characteristics of the surrounding rock of the bracket group. This will affect the determination of the ideal support strength of the hydraulic support group. Therefore, it is necessary to study the coupled mechanical properties of the key parameters of the surrounding rock of the bracket group and select the roof deformation position as the basis for assessment. The roof deformation position is directly above the column of the hydraulic support group.

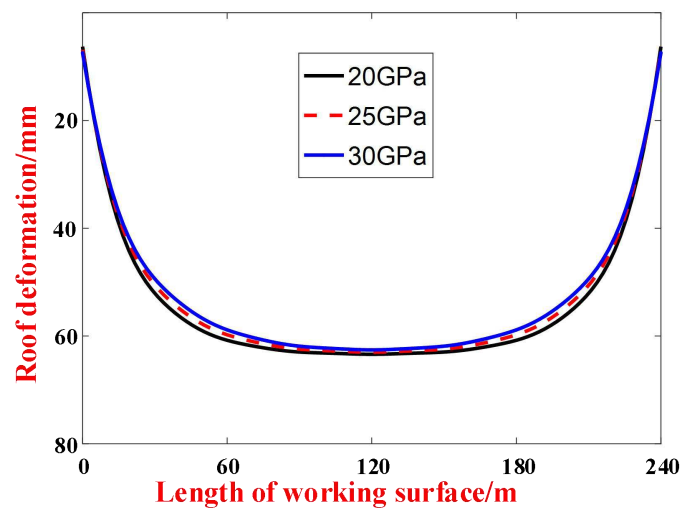

Fig. 6. The deflection of the roof above the hydraulic supports with different Young's modulus values for the roof

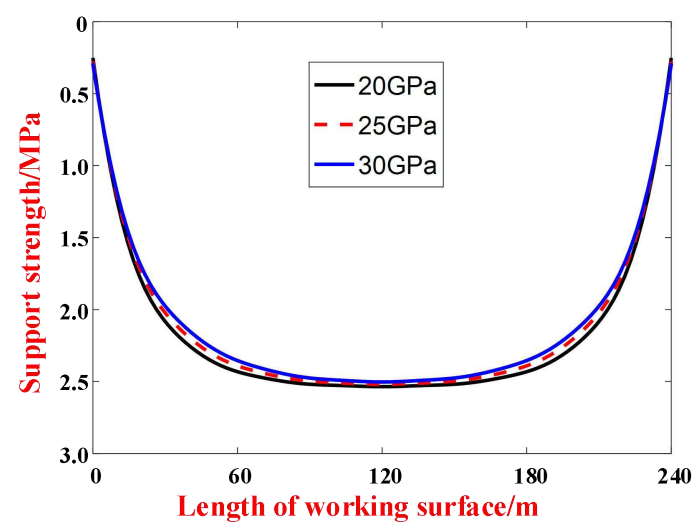

Fig. 7. The support strength of the hydraulic supports with different Young's modulus values for the roof

First, we study the influence of the roof elastic modulus on the roof deformation and the ideal supporting strength of the hydraulic support. Three elastic moduli of $\mathrm{E}=20 \mathrm{GPa}, 25 \mathrm{GPa}$ and $30 \mathrm{GPa}$ were selected. The deformation of the roof above the column and the support strength of the hydraulic support were calculated, as shown in Figure 6 and Figure 7 respectively. Obviously, as the elastic modulus of the roof increases, the deformation of the roof and the ideal support strength of the hydraulic support group decrease. It is worth mentioning that at both ends and in the middle of the working surface, the elastic modulus of the roof has a relatively small influence on the deformation of the roof and the ideal supporting strength of the hydraulic support. However, at $1 / 3$ and $2 / 3$ of the working surface, the elastic modulus of the roof has a 
relatively large influence on the deformation of the roof and the ideal support strength of the hydraulic support. This means that under different working conditions, the support strength of the hydraulic support is related to the position of the working surface, and the support strength and working face position should be adapted to roof deformation and cannot be adjusted uniformly.

The engineering background of this article is the Shendong large mining height fully mechanized mining face of the Shendong Group, which has a large mining height; therefore, more attention is given to the mining height, and the influence of the mining height on the mechanical properties of the surrounding rock of the working face support group is further discussed. Further exploration of the influence of the mining height on the mechanical properties of the surrounding rocks refers to the surrounding rock of the working face support group. Calculations were performed for four working conditions of $6.4 \mathrm{~m}, 7.2 \mathrm{~m}, 8.0 \mathrm{~m}$ and $8.8 \mathrm{~m}$, and the deformation of the roof and the ideal support strength of the hydraulic support were analyzed, as shown in Figure 8 and Figure 9, respectively. Clearly, the mining height has a significant impact on the deformation of the roof and the ideal support strength of the hydraulic support. As the mining height increases, the deformation of the roof increases accordingly. In this context, the ideal support strength of the hydraulic support group also increases. The results show that the mining height is a key factor affecting roof deformation, and as the mining height increases, the ideal support strength for the roof should be increased accordingly.

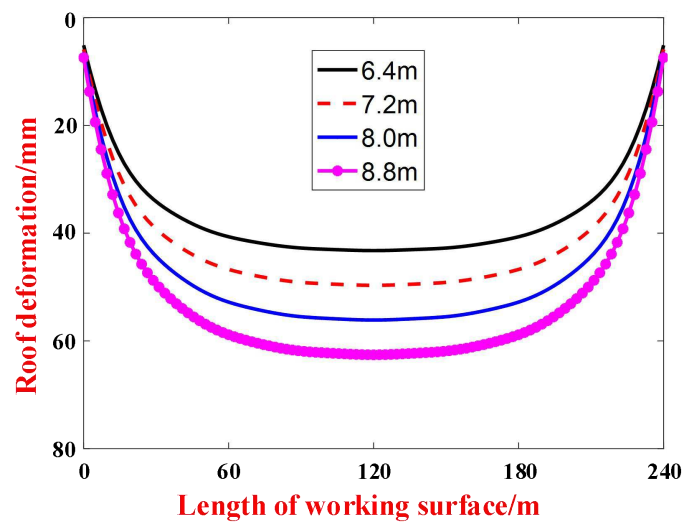

Fig. 8. The deflection of the roof above the hydraulic supports for different mining heights

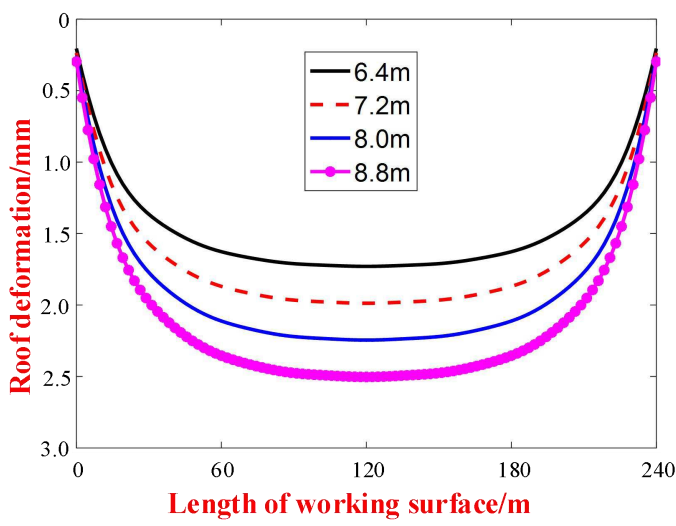

Fig. 9. The support strength of the hydraulic supports for different mining heights

The influence of the working face length on the mechanical properties of the surrounding rock of the working face support group was considered. Here, the length of the working face is calculated as $160 \mathrm{~m}, 200 \mathrm{~m}, 240 \mathrm{~m}, 280 \mathrm{~m}, 320 \mathrm{~m}, 360 \mathrm{~m}$ and $400 \mathrm{~m}$, and the roof deformation curve and ideal support strength curve of the hydraulic support are shown in Figure 10 and Figure 11, respectively. As the length of the working face increases, the deformation of the roof and the ideal support strength of the hydraulic support also increase. In addition, when the length of the working surface is not very large, the maximum deformation of the roof appears in the middle position, and the curve gradient in the middle is more obvious, presenting a "single peak" state. When the length of the working face increases, although the largest deformation of the roof is still in the middle of the roof, the "single peak" becomes 
flat. In this example, when the length of the working surface exceeds $360 \mathrm{~m}$, there is a deformation in the middle of the working face, which is similar to the shape of "one", which means that for the hydraulic support, the ideal support strength is almost the same in the middle section of the working face at this time.

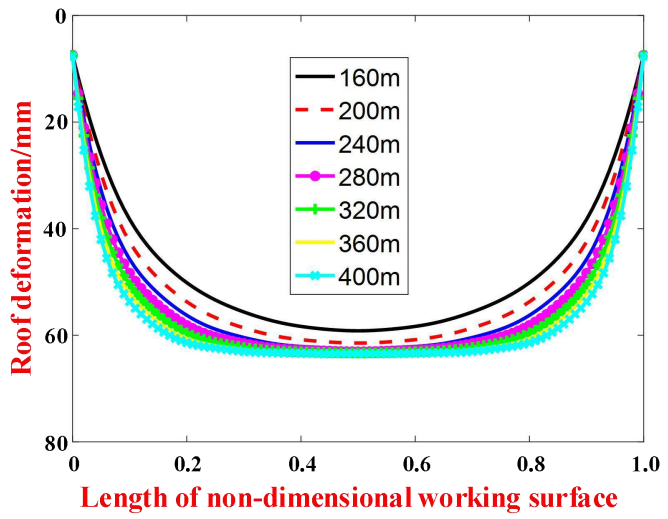

Fig. 10. The deflection of the roof above the hydraulic supports with different working face lengths

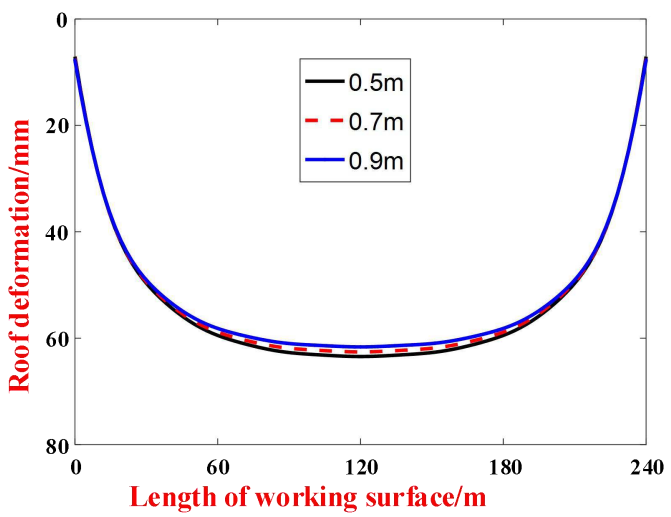

Fig. 12. The deflection of the roof above the hydraulic supports with different tip-to-face distances

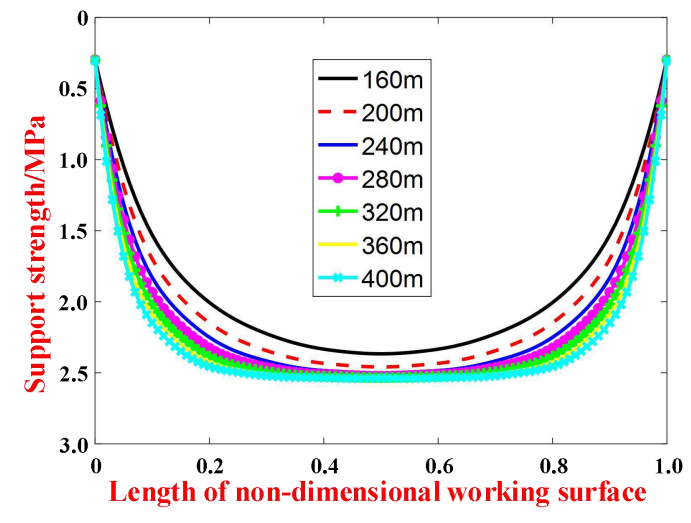

Fig. 11. The support strength of the hydraulic supports with different working face lengths

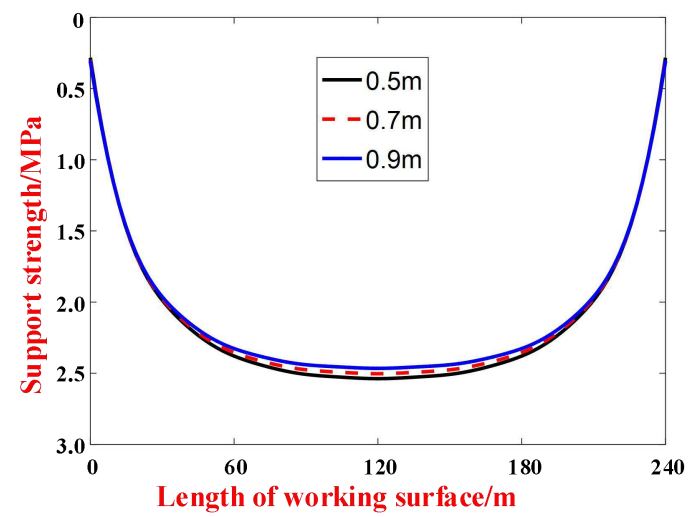

Fig. 13. The support strength of the hydraulic supports with different tip-to-face distances

Further study is needed to determine the impact of the end face distance of the top beam of the hydraulic support on the mechanical characteristics of the coupled model. Under top beam end face distances of $0.5 \mathrm{~m}, 0.7 \mathrm{~m}$ and $0.9 \mathrm{~m}$, the deformation of the roof and the ideal support strength of the hydraulic support are calculated, as shown in Figure 12 and Figure 13, respectively. As illustrated, as the distance between the top beam ends increases, the deformation of the roof decreases, especially in the middle of the working face, and the ideal supporting strength of hydraulic supports also decreases. This means that when the top beam end face distance changes, the adjustment of the ideal support strength of the hydraulic supports at both ends of the working face is smaller than the adjustment amount in the middle.

Subsequently, the influence of the equivalent stiffness of the hydraulic support on the mechanical system between the support and the roof is studied. The deformation of the lower roof and the corresponding ideal support strength curves of the hydraulic support are calculated with the equivalent stiffness of the support at $20 \mathrm{MN} / \mathrm{m}^{3}, 30 \mathrm{MN} / \mathrm{m}^{3}$ and $40 \mathrm{MN} / \mathrm{m}^{3}$, respectively, as shown in Figure 14 and Figure 
15 respectively. It can be seen from the calculation results that as the equivalent rigidity of the hydraulic support group increases, the deformation of the top plate is significantly reduced, which has a positive significance for the stability of the top plate. But at the same time, the ideal support strength of the hydraulic support group increases with the increase of the equivalent stiffness.

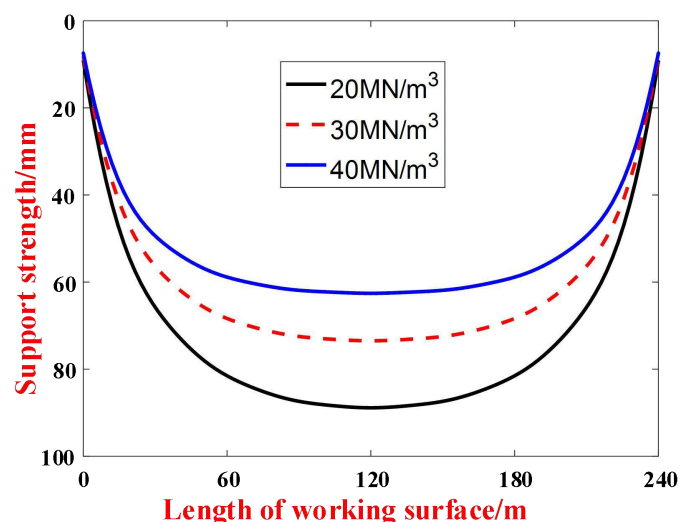

Fig. 14. The deflection of the roof above the hydraulic supports with different stiffness values

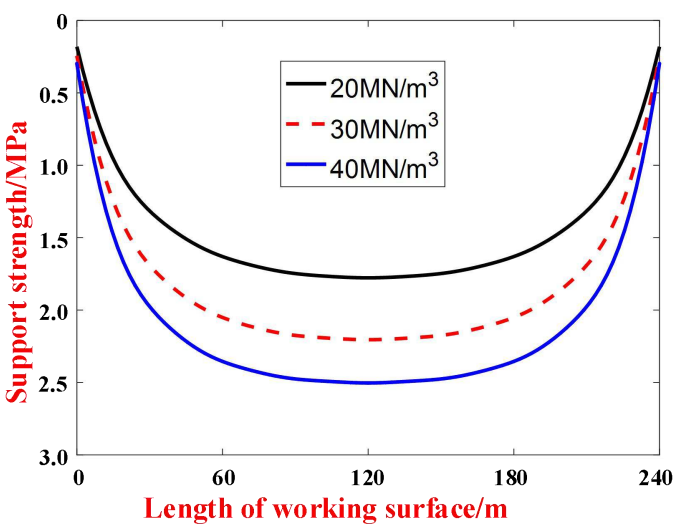

Fig. 15. The support strength of the hydraulic supports with different stiffness values

Further study is needed to determine the effect of the equivalent stiffness of the coal wall on the coupled mechanical system. When the equivalent stiffness of the coal wall is $1 \mathrm{GN} / \mathrm{m}^{2}, 2 \mathrm{GN} / \mathrm{m}^{2}, 3 \mathrm{GN} / \mathrm{m}^{2}, 4 \mathrm{GN} / \mathrm{m}^{2}$ and $5 \mathrm{GN} / \mathrm{m}^{2}$, the roof deformation and the ideal support strength curve of the hydraulic support group are calculated, as shown in Figure 16 and Figure 17, respectively. Obviously, as the equivalent stiffness of the coal wall increases, the deformation of the roof significantly decreases, which shows that the stiffness of the coal wall has a large influence on the deformation of the roof, and the ideal supporting strength of the hydraulic support also significantly decreases. At the same time, as the stiffness of the coal wall increases, the "single peak" of roof deformation also becomes increasingly gentle. Referring to the ideal support strength curve of the hydraulic support group, it can be seen that when the stiffness of the coal wall is quite large, for the hydraulic support group, the support strength in the middle of the working face is very close to the ideal support strength curve.
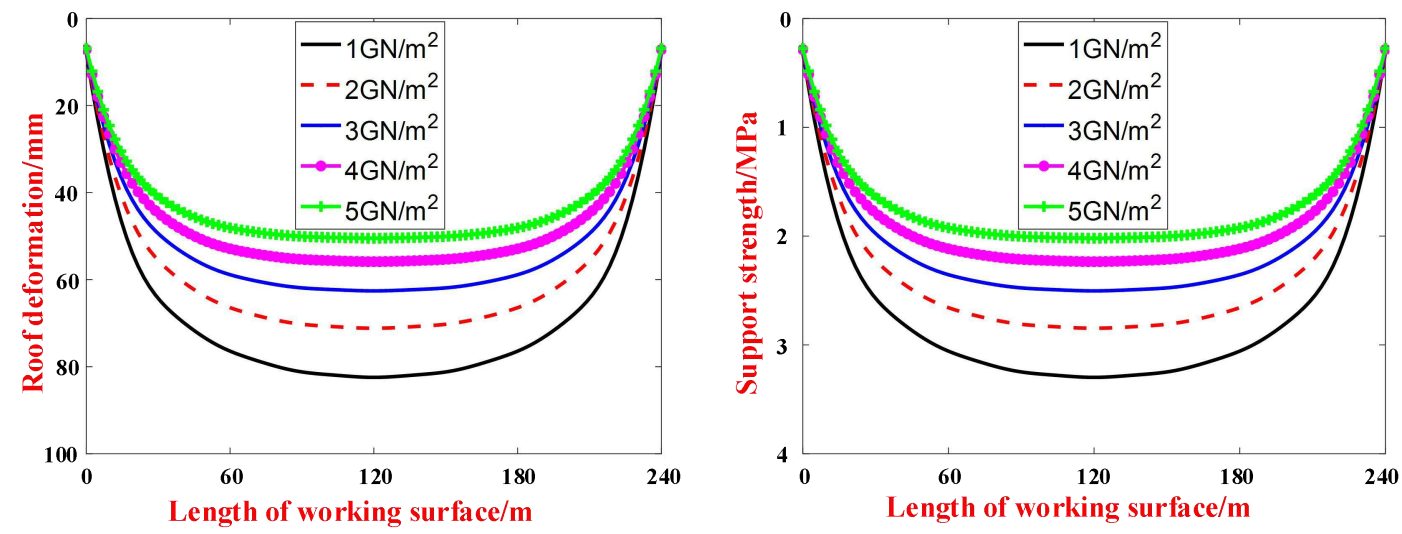
Fig. 16. The deflection of the roof above the hydraulic supports with different stiffness values for the coal wall
Fig. 17. The support strength of the hydraulic supports with different stiffness values for the coal wall

Finally, the effect of the direct top thickness on the mechanical properties of the coupled system is studied. Under direct roof thicknesses of $7.3 \mathrm{~m}, 9.3 \mathrm{~m}$ and $11.3 \mathrm{~m}$, the calculated roof deformation and the ideal support strength curve of the hydraulic support group are shown in Figure 18 and Figure 19, respectively. Visibly, as the thickness of the direct top increases, the equivalent load on the roof decreases. Thus, as the thickness of the direct top increases, the deformation of the roof decreases, especially in the middle of the working face. Under this condition, as the thickness of the direct top increases, the ideal support strength of the hydraulic support group also decreases.

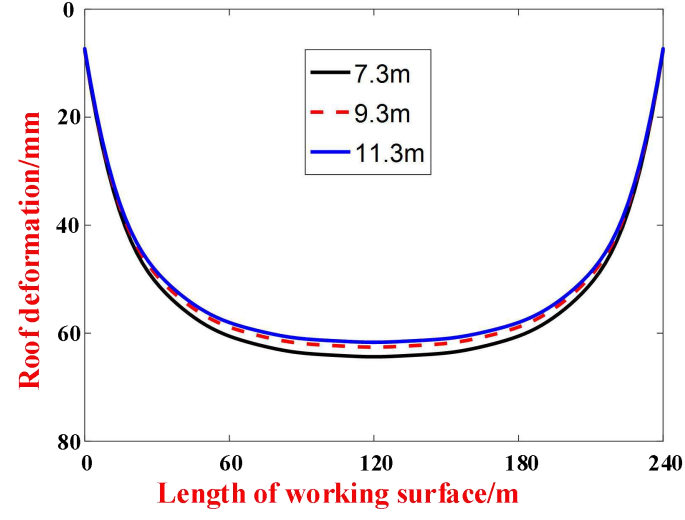

Fig. 18. The deflection of the roof above the hydraulic supports with different immediate roof thicknesses

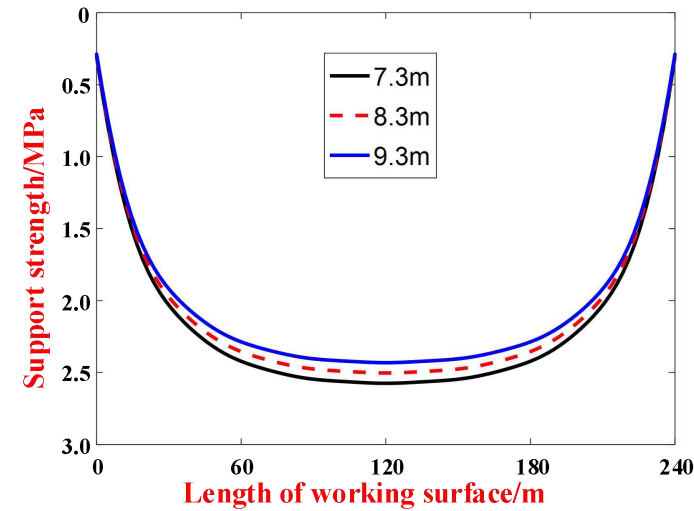

Fig. 19. The support strength of the hydraulic supports with different immediate roof thicknesses

\section{Analysis of on-site experimental test results}

\subsection{Experimental test plan and corresponding sensor setup}

The hydraulic support group of the 12401 working face of the Shendong Group Shangwan Coal Mine was used as the experimental test object to verify the calculation results of the theoretical model. The length of the working surface is 260 $\mathrm{m}$, the excavation length is $5400 \mathrm{~m}$, the JOY07 L08 coal shearer produced by JOY Company is chosen and 149 ZY21000/36.5/80D shielded hydraulic supports are selected as working face hydraulic supports. The rated initial support force is $35 \mathrm{MPa}$, the rated working resistance is $47.6 \mathrm{MPa}$ and the supporting strength is $1.60 \mathrm{MPa}$.

The experimental implementation scheme is shown in Figure 20. The support near the air inlet tunnel is defined as support No.1, the supports are serially numbered to the nearest air return roadway, the support position of support No.1 is defined as measuring point 1 and the support position of the tail bracket is defined as measuring point 15, for a total of 15 measuring points. In the experiment, the data of the hydraulic support controller are collected and extracted every five minutes. A rock strain gauge sensor is pasted at each measuring point, and the sensor is used to measure the pressure of the roadway roof, as shown in Figure 21. Meanwhile, the roof separation indicator is used to calculate the subsidence of the roadway roof. 


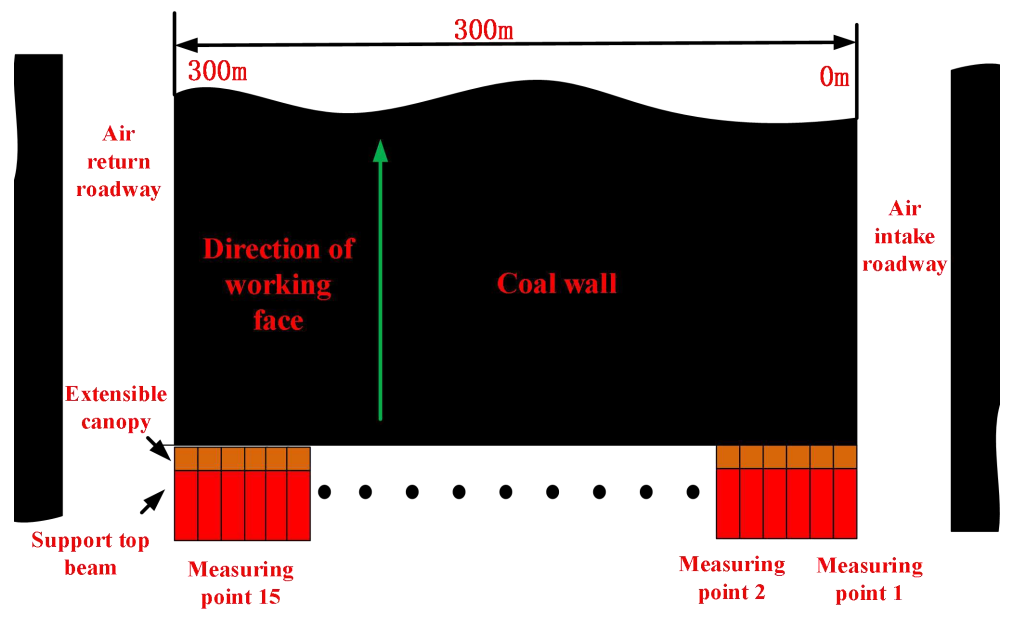

Fig. 20. Experimental sensor arrangement

In the experiment, the roof separation indicator BX120-10AA $(100 \times 5 \mathrm{~mm})$ produced by Zhejiang Taizhou Huangyan Juxing Electrical Measuring Component Factory was used. The rock strain gauge sensor tests the stress of the supporting roof, and the main technical parameters of the strain gauge sensors are shown in Table 1.
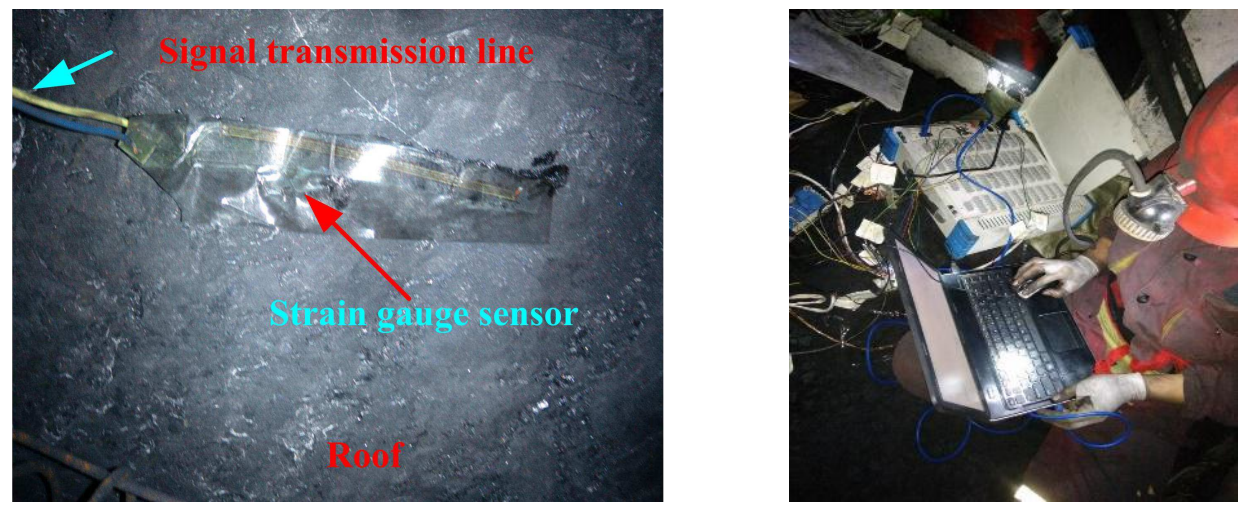

Fig. 21. Strain gage sensor installation and data acquisition system

Table. 1. Main technical parameters of the strain gauge sensor

\begin{tabular}{cccccccc}
\hline Accurac & Safety & Temperatu & Zero point & Sensitivity & Monolithi & Sensitivit & Source \\
$\mathrm{y}$ & overloa & re range & $\begin{array}{c}\text { temperature } \\
\text { temperature }\end{array}$ & $\mathrm{c}$ & y factor & voltage \\
& $\mathrm{d}$ & & $\mathrm{drift}$ & $\mathrm{drift}$ & $\begin{array}{c}\text { resistance } \\
\text { value }(\omega)\end{array}$ & \\
& & & & & & \\
\hline $0.02 \% \mathrm{~F}$ & $150 \% \mathrm{~F}$ & $-30 \sim 70^{\circ} \mathrm{C}$ & $<$ & $<$ & $120 \pm 0.2$ & $2.08 \pm 1 \%$ & $\mathrm{DC} 12 \sim 30$ \\
$\mathrm{~s}$ & $\mathrm{~s}$ & & $0.05 \% \mathrm{Fs} / 10$ & $0.03 \% \mathrm{Fs} / 10$ & & & $\mathrm{~V}$ \\
& & & ${ }^{\circ} \mathrm{C}$ & ${ }^{\circ} \mathrm{C}$ & & & \\
\hline
\end{tabular}

After the corresponding strain gauge sensor was installed and connected to the corresponding static strain gauge, according to the plan, the hydraulic support group with a very large mining height was lifted to make it fully supported, and data collection began.

\subsection{Comparative analysis of roof subsidence of the working face}

A comparison of the experimental test results and the theoretical roof 
deformation results is shown in Figure 22. The deformation of the roof under support strengths of $1.7 \mathrm{MPa}$ and $2.0 \mathrm{MPa}$ is compared, and the theoretical calculation error is also given. Overall, the theoretical roof deformation results are consistent with the roof deformation trend obtained from the experimental results. However, the experimentally measured deformation result is greater than the theoretical value. In particular, the measurement points at both ends have the largest errors. It is speculated that the theoretical model cannot be truly constrained by using theoretical elastic boundary conditions, and the influencing factors of the actual working face roof are very complicated, but this error is within the allowable range.

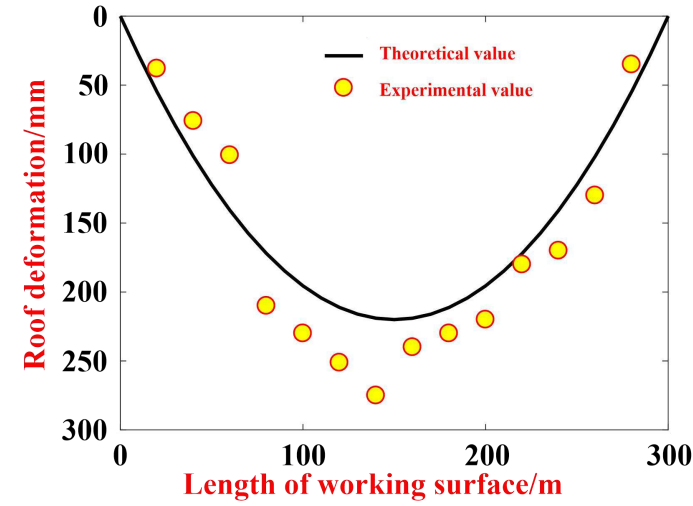

(a) Supporting strength of $1.7 \mathrm{MPa}$

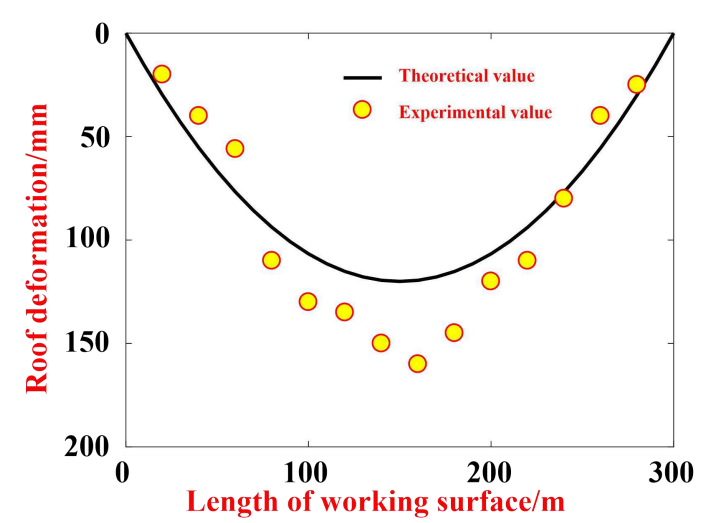

(b)Supporting strength of $2.0 \mathrm{MPa}$

Fig. 22. Comparison of theoretical and experimental values of roof deformation in the working face

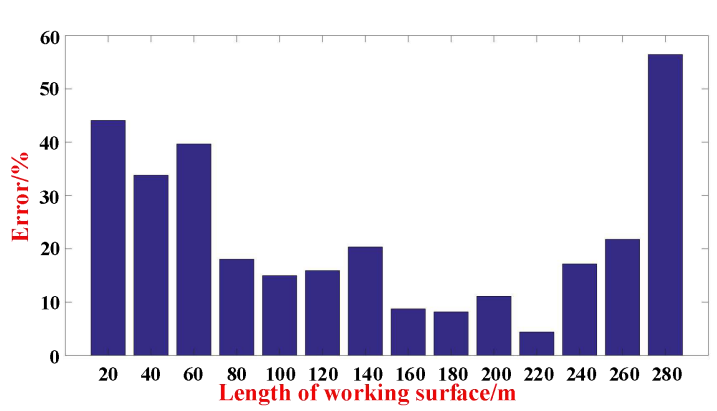

(a) Supporting strength is $1.7 \mathrm{MPa}$

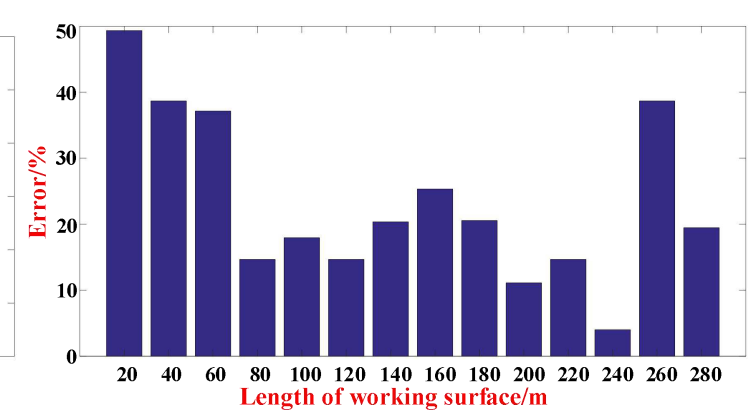

(b)supporting strength is $2.0 \mathrm{MPa}$

Fig. 23. Experimental and theoretical error rates for different support strengths

4.3 Comparative analysis of the stress distribution on the roof of the working face
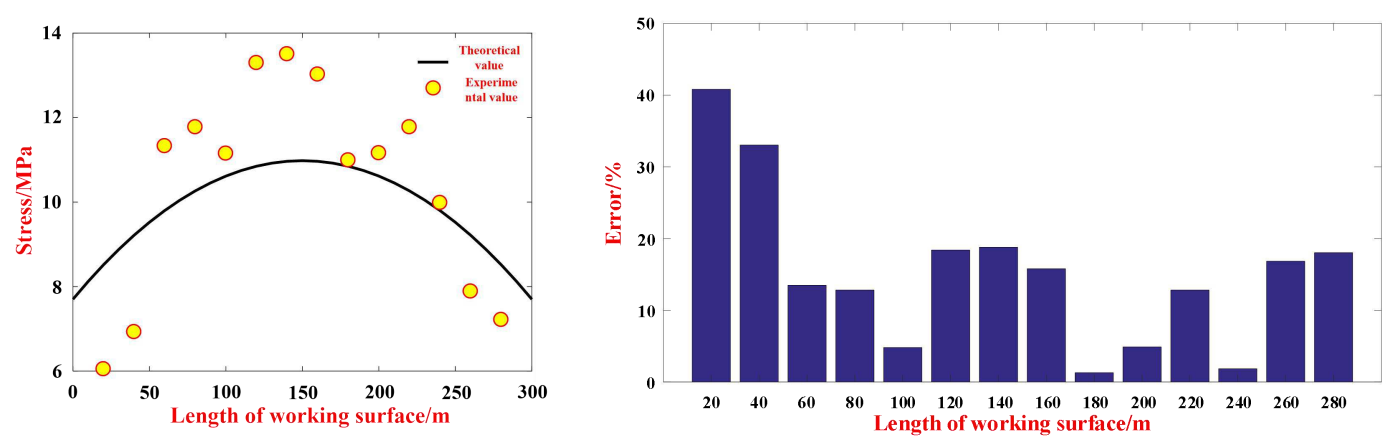

Fig. 24. Comparison of the theoretical and experimental values of the stress distribution 
The roof pressure of the working face is compared with the experimental results, as shown in Figure 24. Obviously, the calculation result can predict the roof pressure well, but the overall calculated value is smaller than the experimental value, and the error is greatest near the side of the roadway, which is caused by the more complicated constraints there.

\section{Conclusion}

Because the hydraulic support group and the surrounding rock in a fully mechanized mining face often do not exist in isolation, they compose a mutually coupled system. Based on the mining conditions of the Shangwan Coal Mine of the Shendong Group, research on the coupled mechanical characteristics of the hydraulic support group and the surrounding rock in a fully mechanized mining face was carried out, and the following research results were obtained:

(1) Considering the elastic effect of the coal at the front of the working face and the roadways at both ends, hydraulic supports are treated as elastic foundations, and a coupled mechanical model of the surrounding rock of the working face support group is established;

(2) Based on the coupled mechanical model of the surrounding rock of the bracket group, the influence of parameters such as the roof elastic modulus, mining height, working face length, end face distance, support stiffness, coal wall stiffness and direct roof thickness on roof deformation is discussed. According to these parameters, the ideal support strength of the hydraulic support is given.

(3) The elastic modulus of the surrounding rock, the distance between the top beam end faces, the equivalent stiffness of the coal wall, the thickness of the direct roof and the ideal support strength are negatively related to the control of the deformation of the roof, and the mining height, working face length and ideal support strength are positively related to the control of the deformation of the roof.

\section{Acknowledgments}

This work was supported by the China Postdoctoral Science Foundation(No. 2020M672089), National Key Research and Development Plan of Ministry of Science and Technology of the People's Republic of China (2017YFC0804305) and the Major Science and Technology Innovation Projects in Shandong Province (2019SDZY04).

\section{References}

[1] Qian Minggao, Miao Xiexing, He Fulian, Liu Changyou. Mechanism of coupling effect between supports in the workings and the rocks [J]. Journal of China Coal Society,1996(01):40-44.

[2] Liu Changyou, Qian Minggao, Cao Shenggen, et al. Influencing mechanism of immediate roof on the relation between supports in the working and surrounding rocks $[\mathrm{J}]$. Journal of China Coal Society,1997(05):25-30.

[3] Wu Jian,Zhang Yong. The new concept of relationship between support and surrounding-rock in longwall top-coal caving faces[J]. Journal of China Coal Society, 2001(04):350-355. 
[4] Wu Y P, Xie P S, Ren S G, et al, Three-dimensional strata movement around coal face of steeply dipping seam group[J]. Journal of Coal Science \& Engineering(China), 2008, 3: 352-355.

[5] Wu Y P. Analysis for interaction of supports and surrounding rock of gateways in longwall mining[J]. Journal of Coal Science \& Engineering(China), 2001, 2: 30-35.

[6] Lai X P, Wu Y P. Application of integrated intelligent methodology to predict stability and supporting decision in underground drift[J]. Journal of Coal Science \& Engineering(China), 2000, 2: 40-44.

[7] Wang Guofa, Liu Junfeng, Ren Huaiwei. Design and optimization of high seam-caving coal hydraulic support based on model of support and wall rock coupling. Journal of China Coal Society,2011,36(01):145-151.

[8] Wang Guofa, Pang Yihui . Relationship between hydraulic support and surrounding rock coupling and its application $[\mathrm{J}]$. Journal of China Coal Society, 2015,40( 1) :30-34.

[9] He Fulian, Chen Dongdong, Xie Shengrong. The kDL effect on the first fracture of main roof with elastic foundation boundary[J]. Chinese Journal of Rock Mechanics and Engineering,2017,36(06):1384-1399.

[10] Xie Shengrong, Chen Dongdong, Sun Yanding, Gao Mingming, Sun Yunjiang, Shi Wei. Analysis on thin plate model of basic roof at elastic foundation boundary( I) : First breaking[J]. Journal of China Coal Society,2016,41(06):1360-1368.

[11] Chen Dongdong, He Fulian, Xie Shengrong, Gao Mingming, Song Haizheng. First fracture of the thin plate of main roof with three sides elastic foundation boundary and one side coal pillar[J]. Journal of China Coal Society,2017,42(10):2528-2536.

[12] Xie Shengrong, Chen Dongdong, Gao Mingming, Sun Yanding, Wu Jingke, Zhang Tao. Fracture regularity of thin plate model of main roof with elastic foundation boundary for backfill mining $[\mathrm{J}]$. Journal of China Coal Society,2017,42(09):2270-2279.

[13] Xu Yajun. Coupling Analysis of Powered Support and Roof in Mining Face[J]. Coal Mining Technology,2015,20(03):39-42.

[14] Xu Yajun, Wang Guofa. Supporting principle and bearing characteristics of hydraulic powered roof support groups[J]. Chinese Journal of Rock Mechanics and Engineering, 2017,36(S1):3367-3373.

[15] Xu Yajun, Wang Guofa, Zhang Jinhu, et al. Theory and application of supporting stress fields of hydraulic powered support groups in fully mechanized mining face with large mining height based on elastic supporting beam model[J]. Chinese Journal of Rock Mechanics and Engineering, 2018,37(05):1226-1236.

[16]Liu Hongwen, Lin Jianxing, Cao Manling. Plate and Shell Theory[M]. Hangzhou: Zhejiang University Press, 1987.

[17]Zhang Xiong. Computational Dynamics[M]. Beijing: Tsinghua University Press, 2015.

[18] Qian Minggao. Mine pressure and rock formation control [M]. Xuzhou: China University of Mining and Technology Press, 2010: 148-151. 
Figures
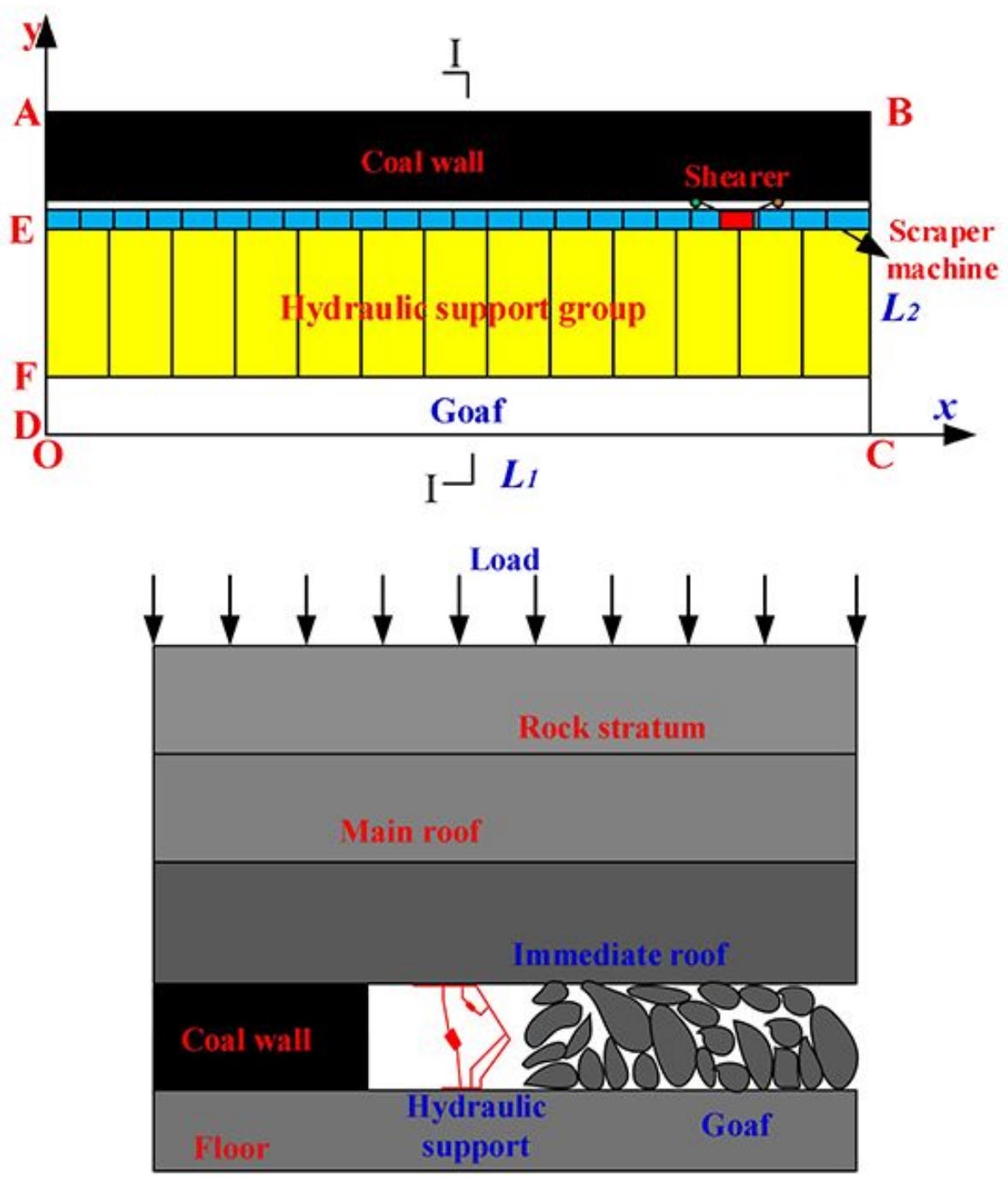

Figure 1

Support group surrounding the coupled rock system in a fully mechanized mining face 


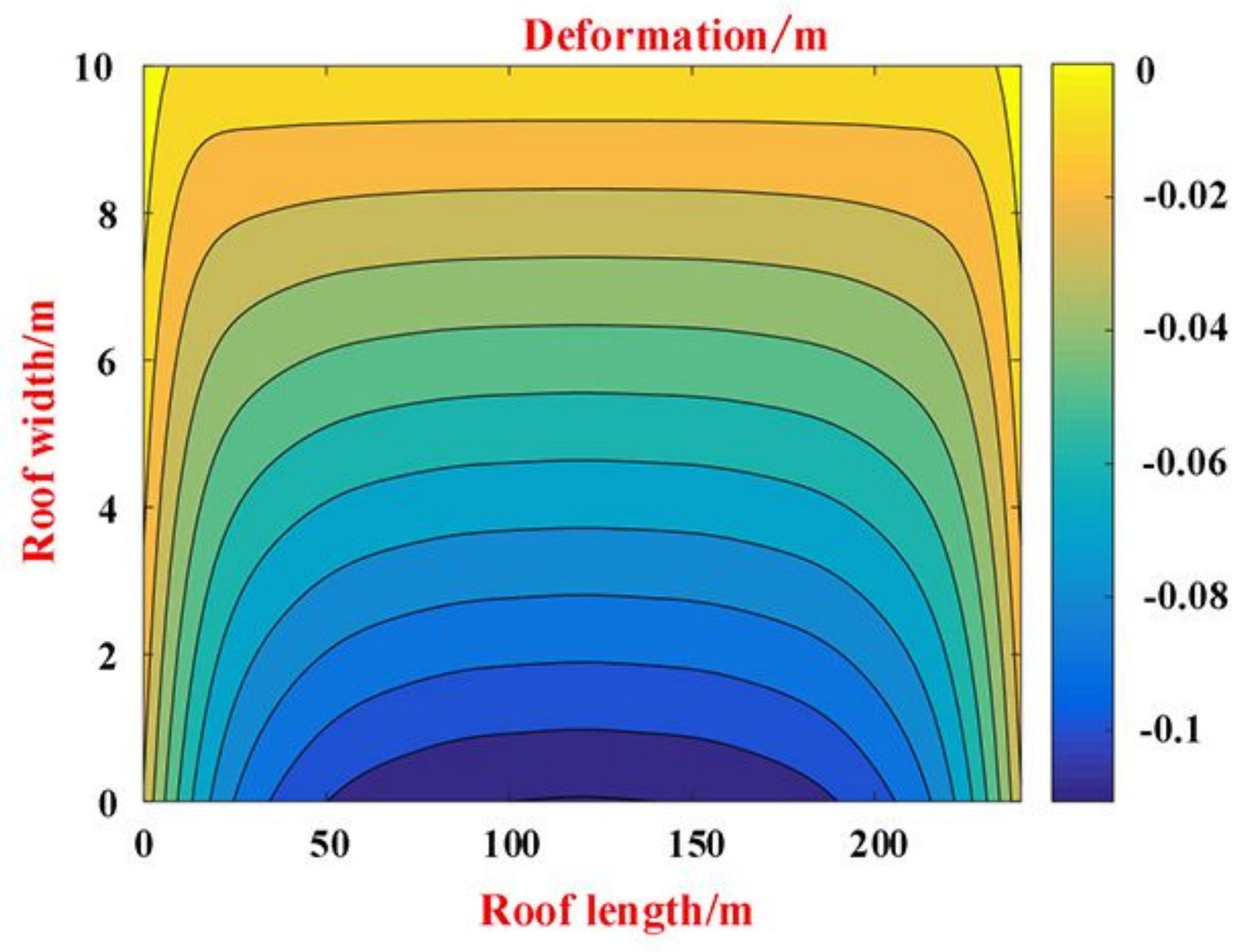

Figure 2

The contour of the deflection of the roof 

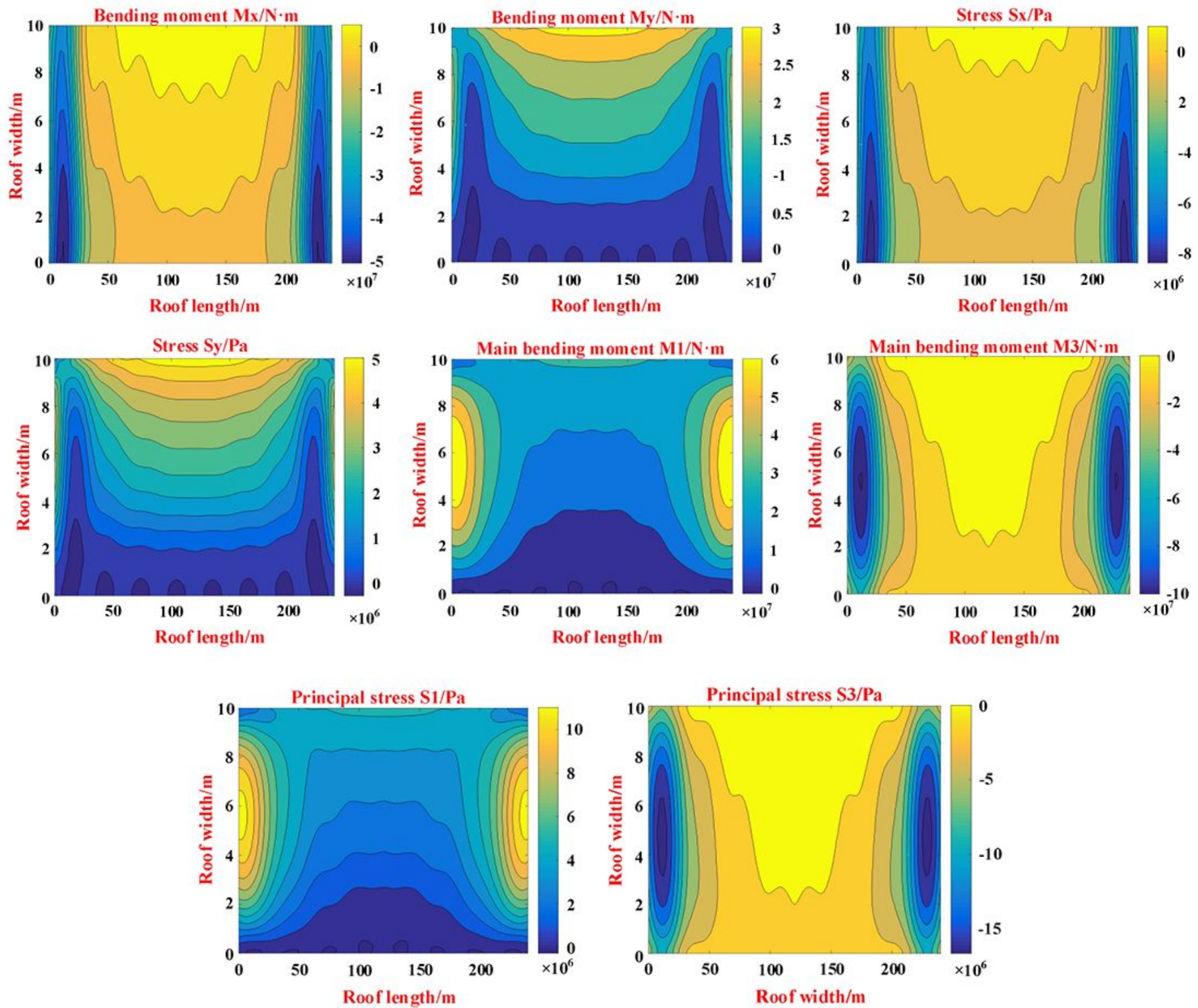

Figure 3

Contour of the moment and stress of the roof 


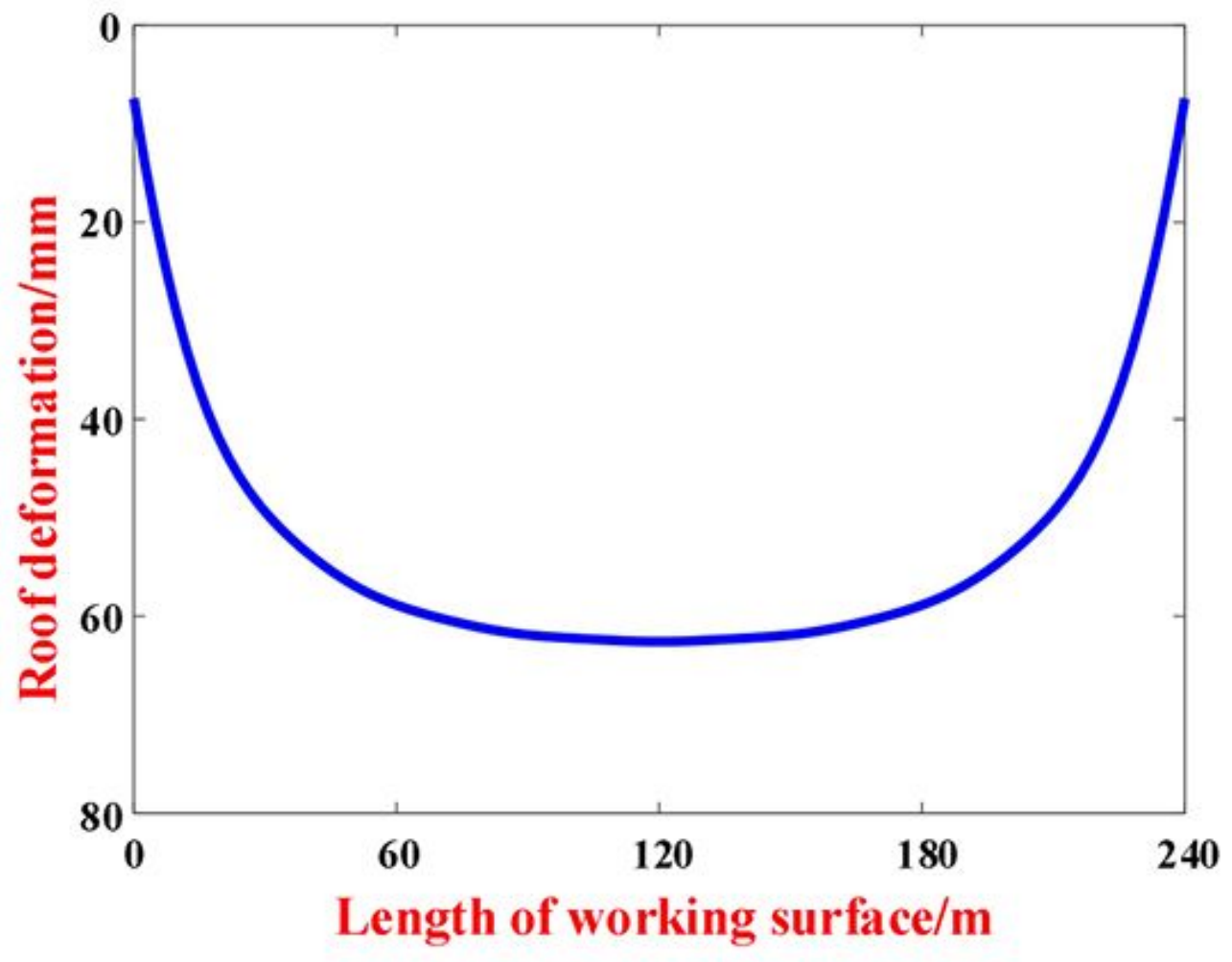

Figure 4

The deflection of the roof above the hydraulic supports 


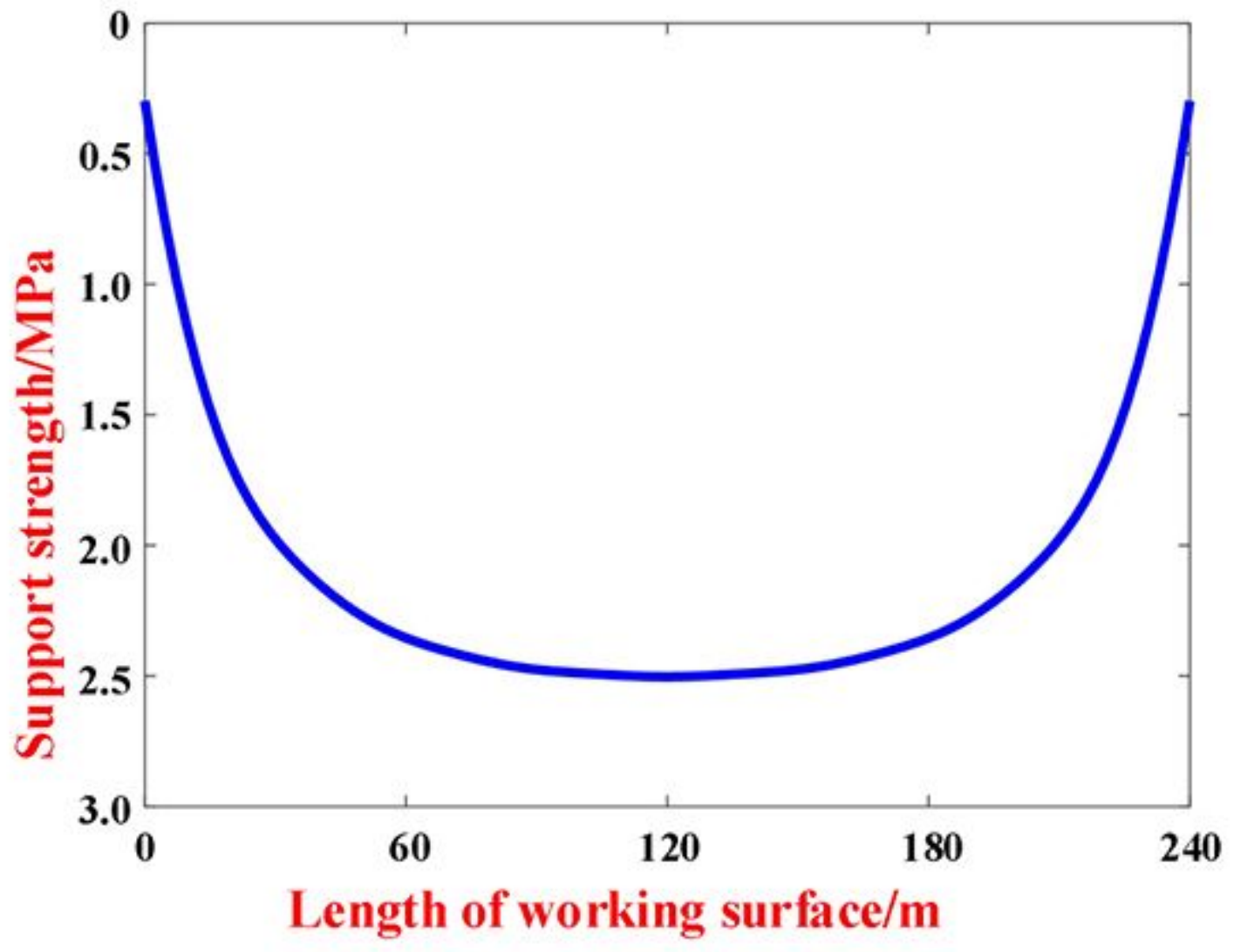

Figure 5

The support strength of the hydraulic supports

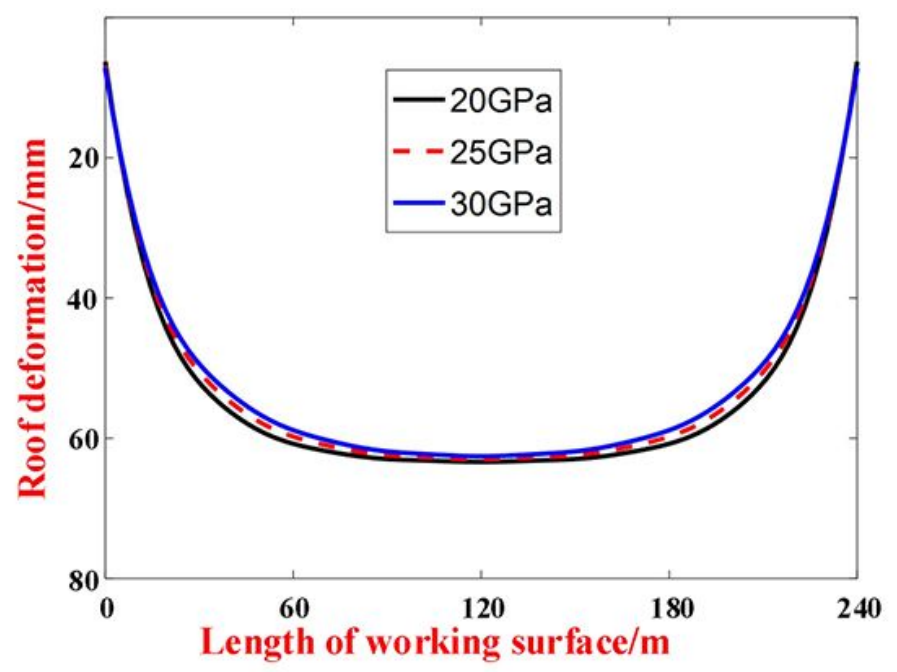

Figure 6 
The deflection of the roof above the hydraulic supports with different Young's modulus values for the roof

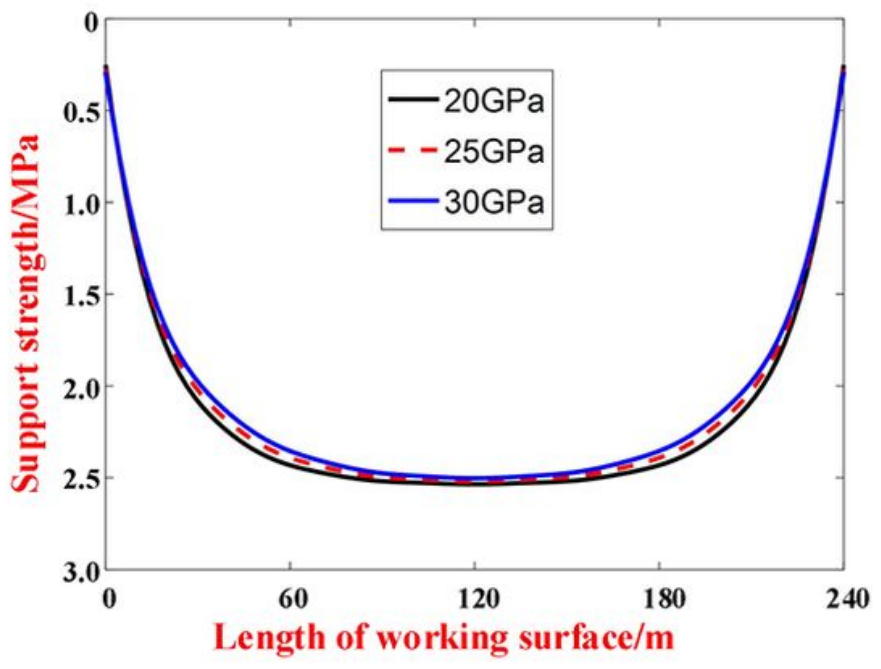

\section{Figure 7}

The support strength of the hydraulic supports with different Young's modulus values for the roof

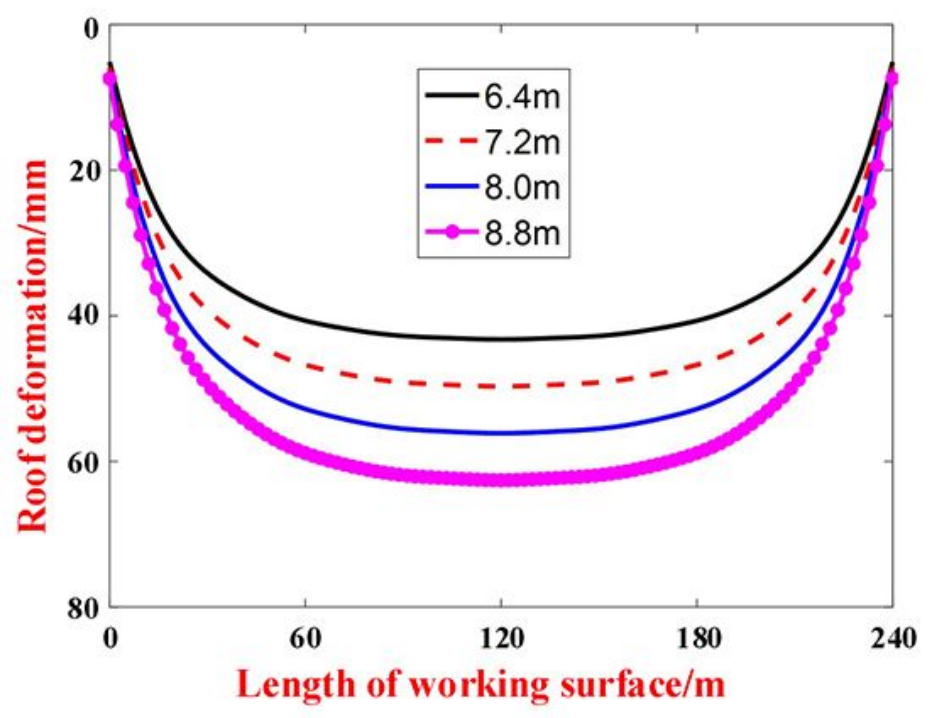

Figure 8

The deflection of the roof above the hydraulic supports for different mining heights 


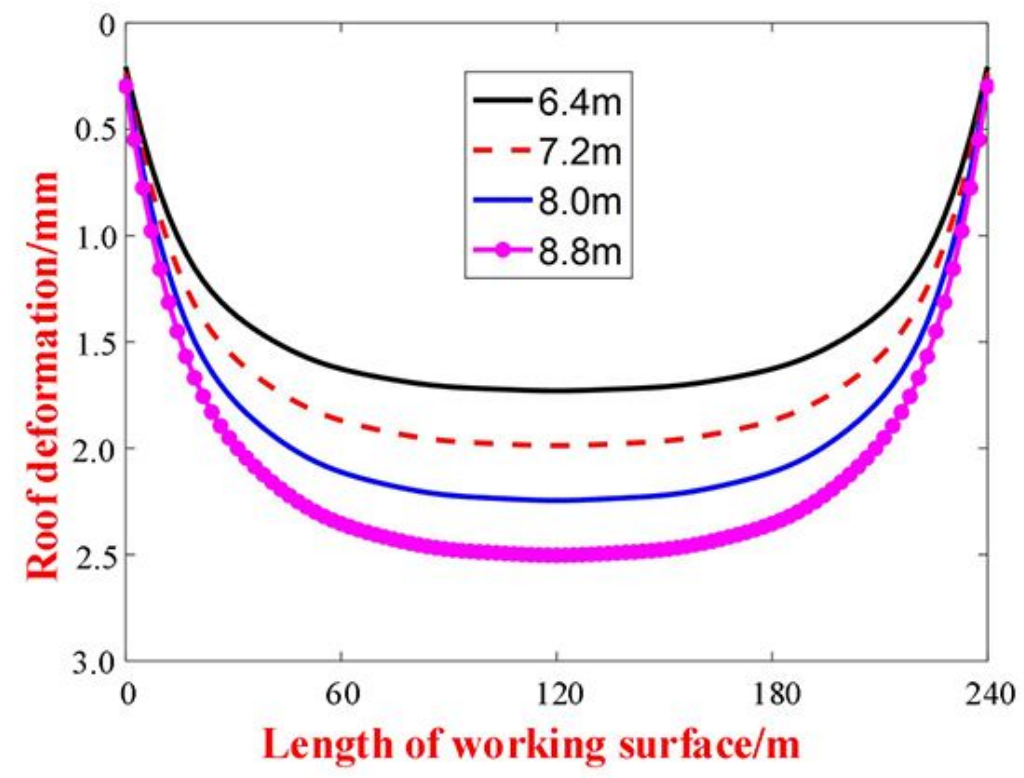

Figure 9

The support strength of the hydraulic supports for different mining heights

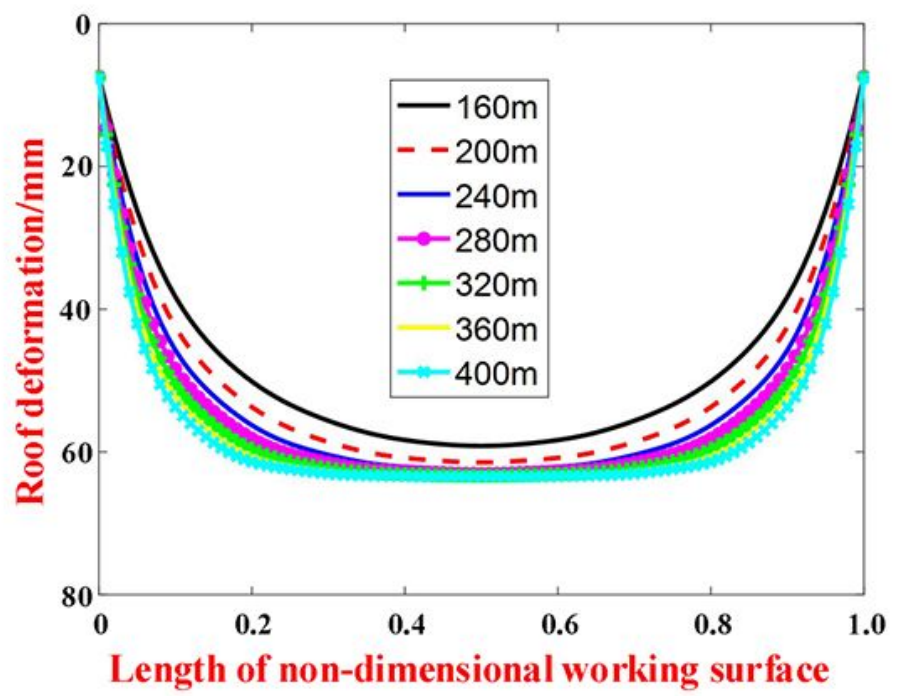

Figure 10

The deflection of the roof above the hydraulic supports with different working face lengths 


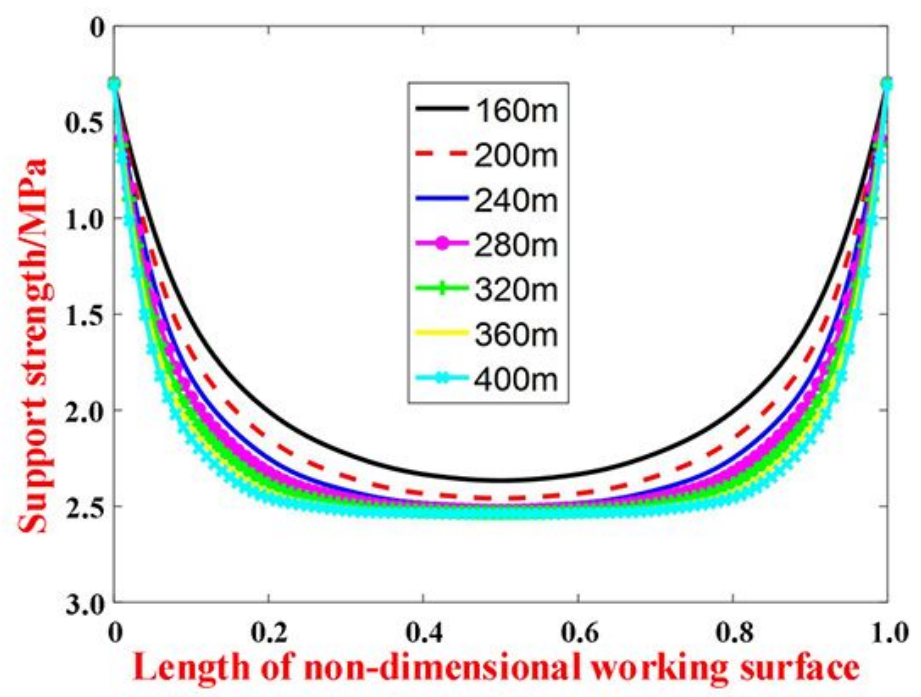

Figure 11

The support strength of the hydraulic supports with different working face lengths

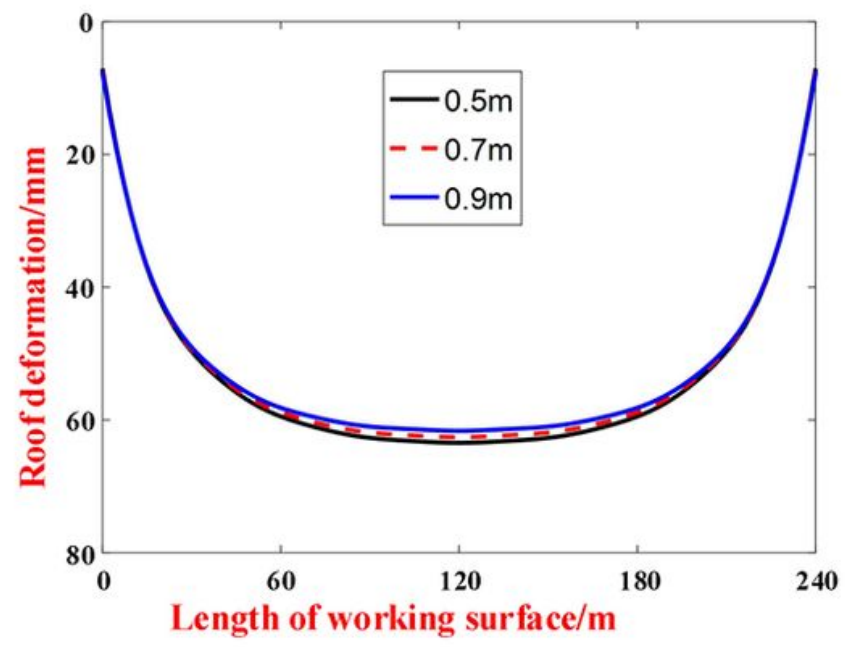

Figure 12

The deflection of the roof above the hydraulic supports with different tip-to-face distances 


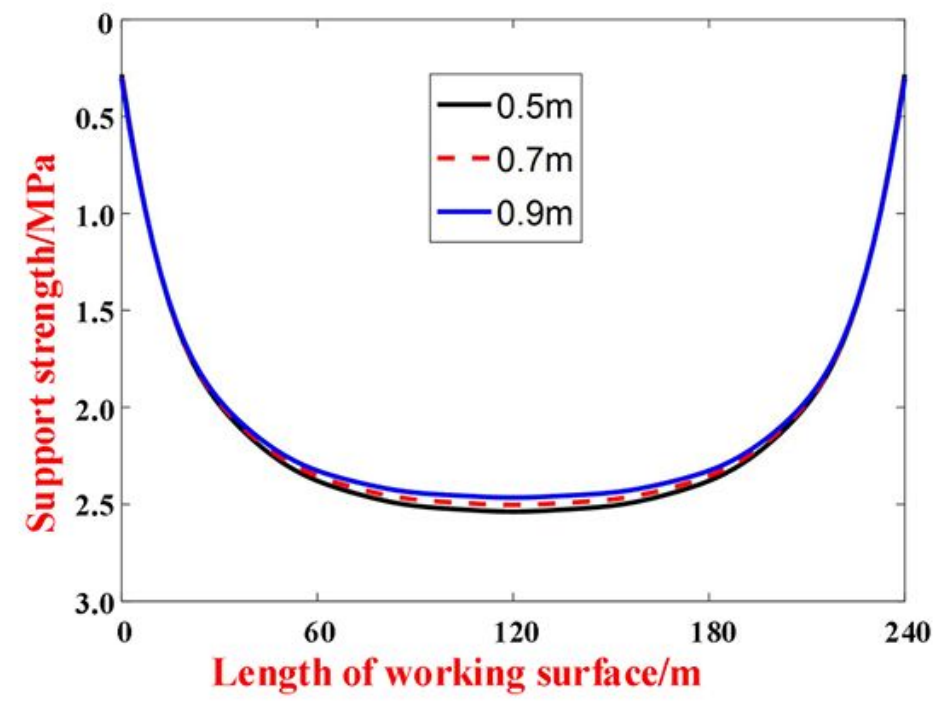

Figure 13

The support strength of the hydraulic supports with different tip-to-face distances

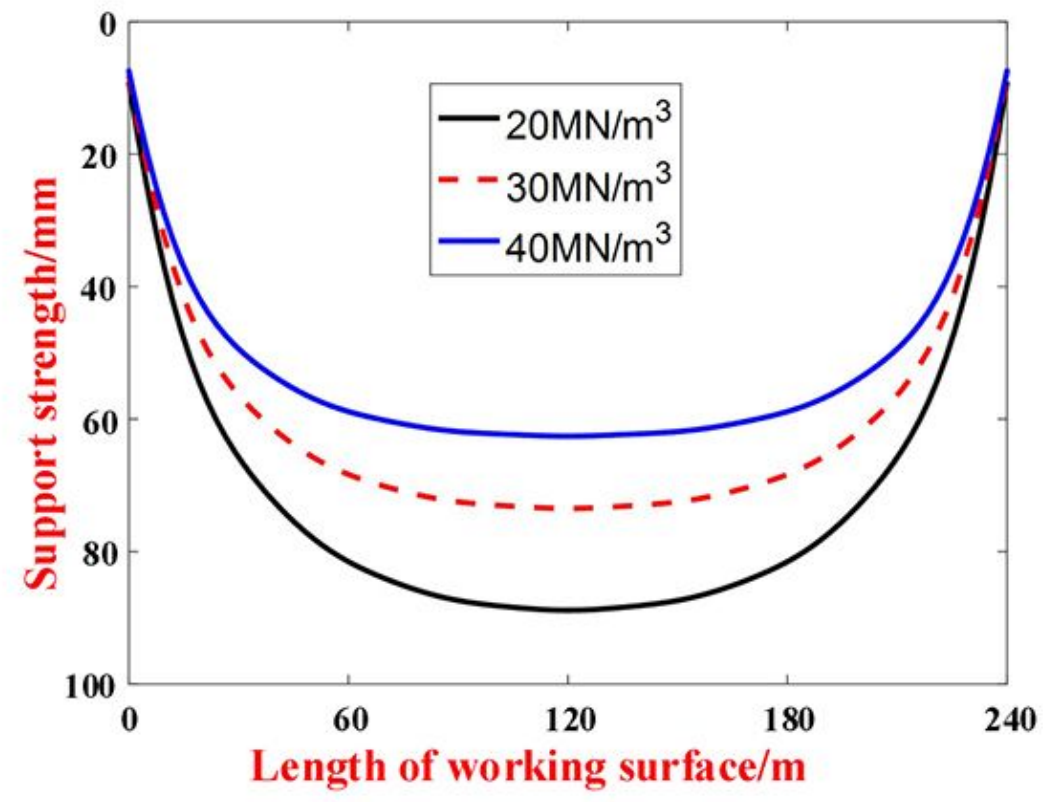

Figure 14

The deflection of the roof above the hydraulic supports with different stiffness values 


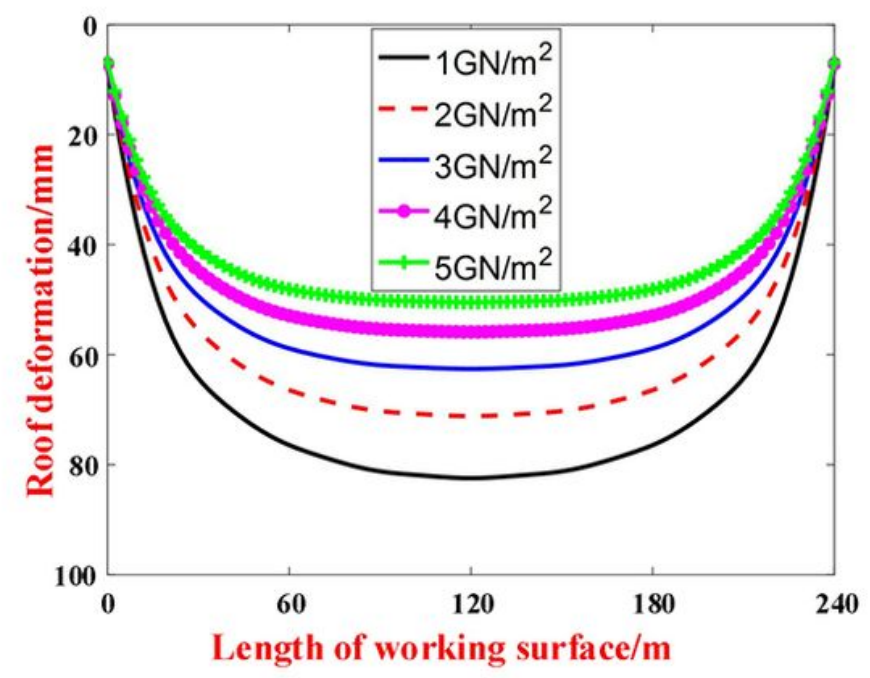

Figure 16

The deflection of the roof above the hydraulic supports with different stiffness values for the coal wall

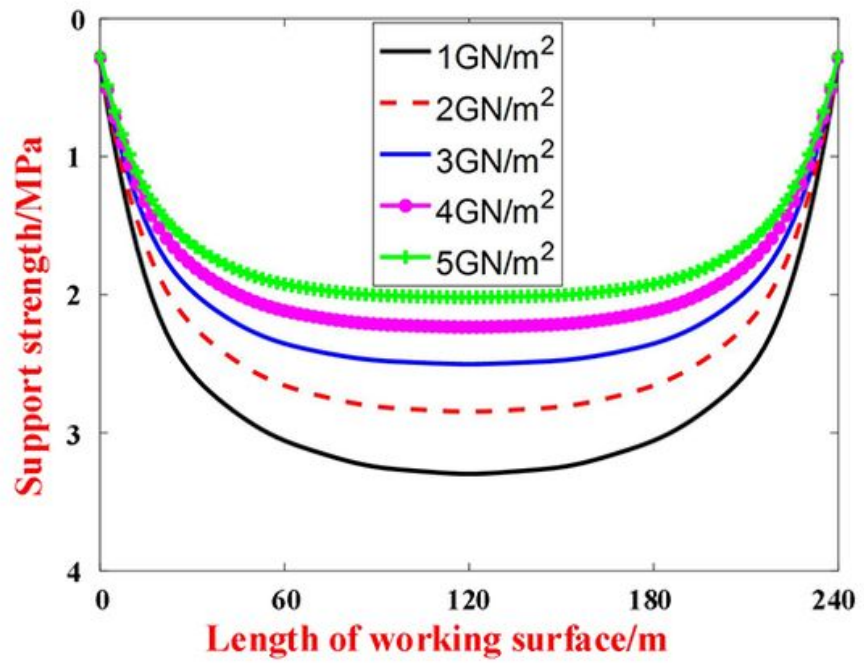

Figure 17

The support strength of the hydraulic supports with different stiffness values for the coal wall 


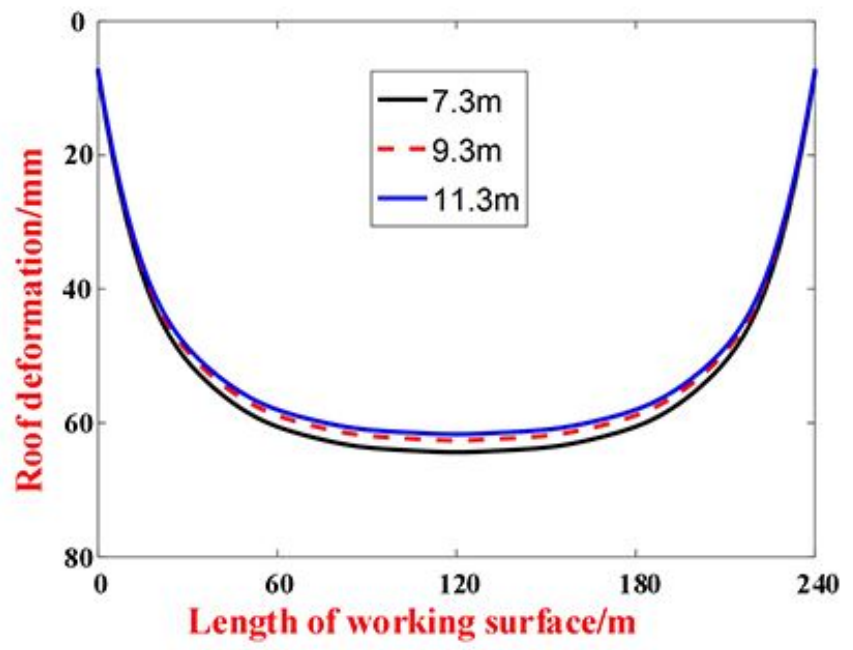

Figure 18

The deflection of the roof above the hydraulic supports with different immediate roof thicknesses

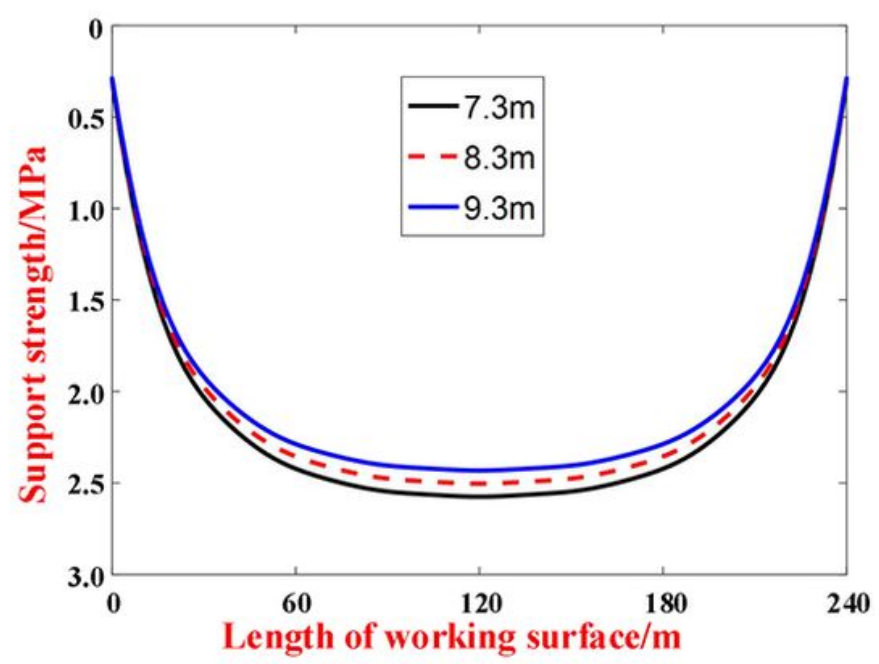

Figure 19

The support strength of the hydraulic supports with different immediate roof thicknesses 


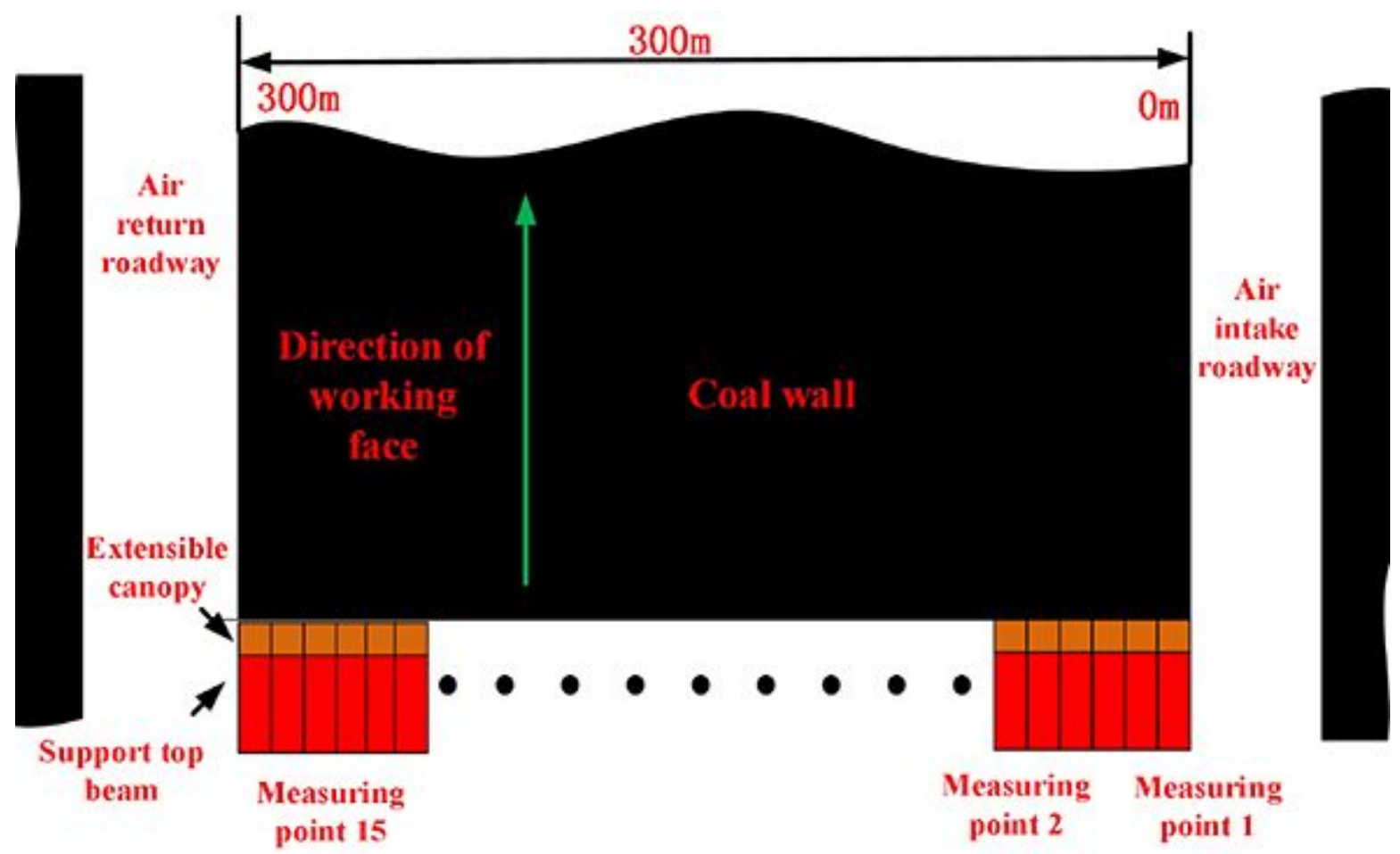

Figure 20

Experimental sensor arrangement

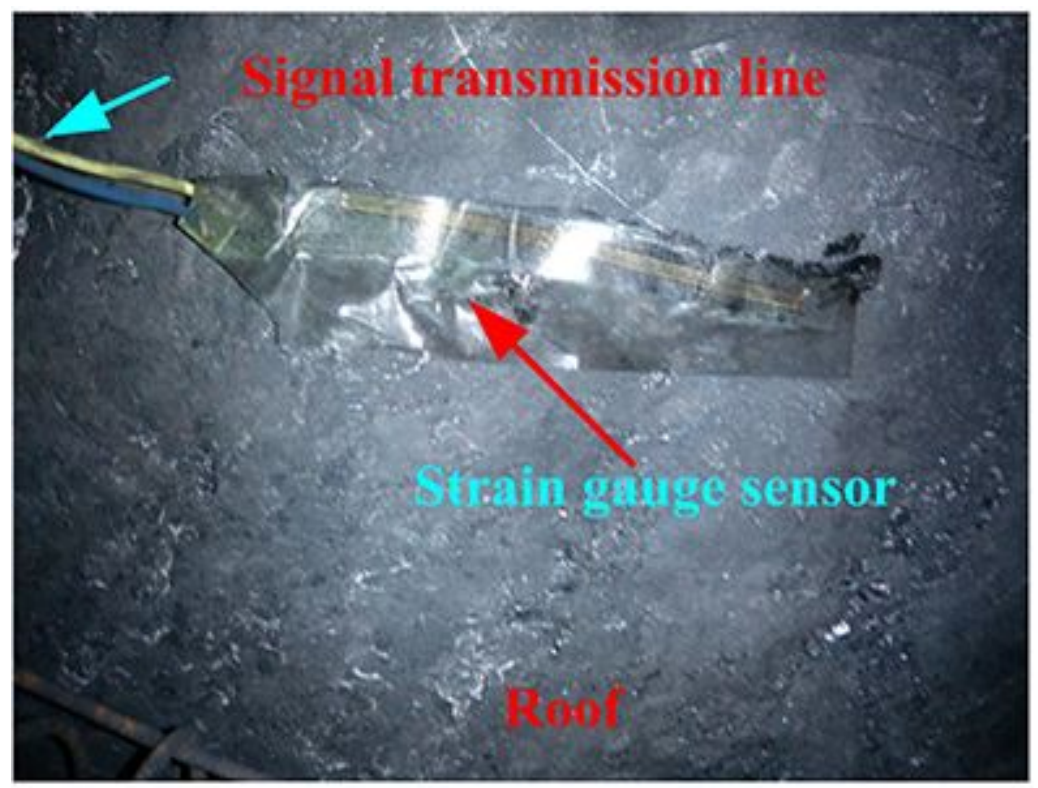

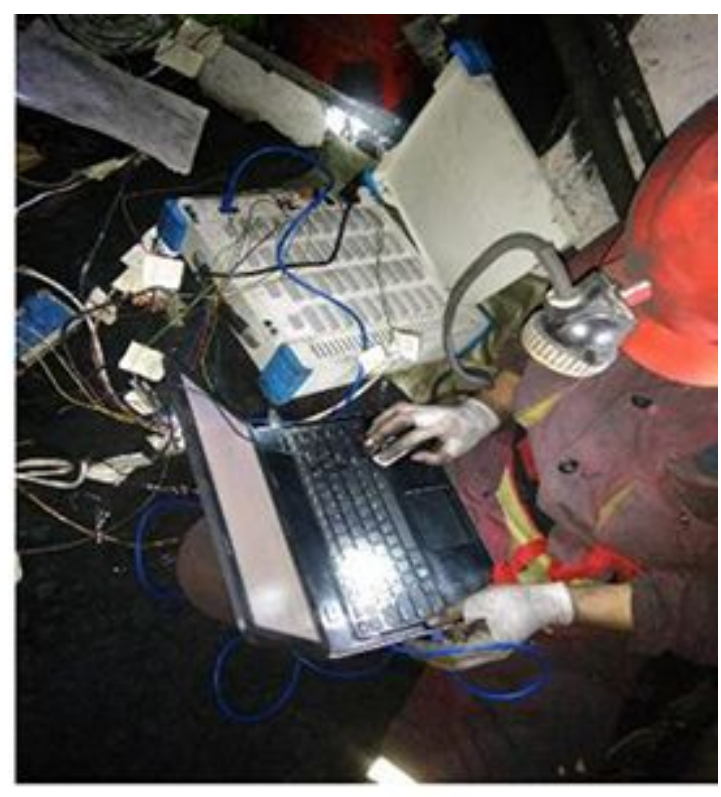

Figure 21

Strain gage sensor installation and data acquisition system 


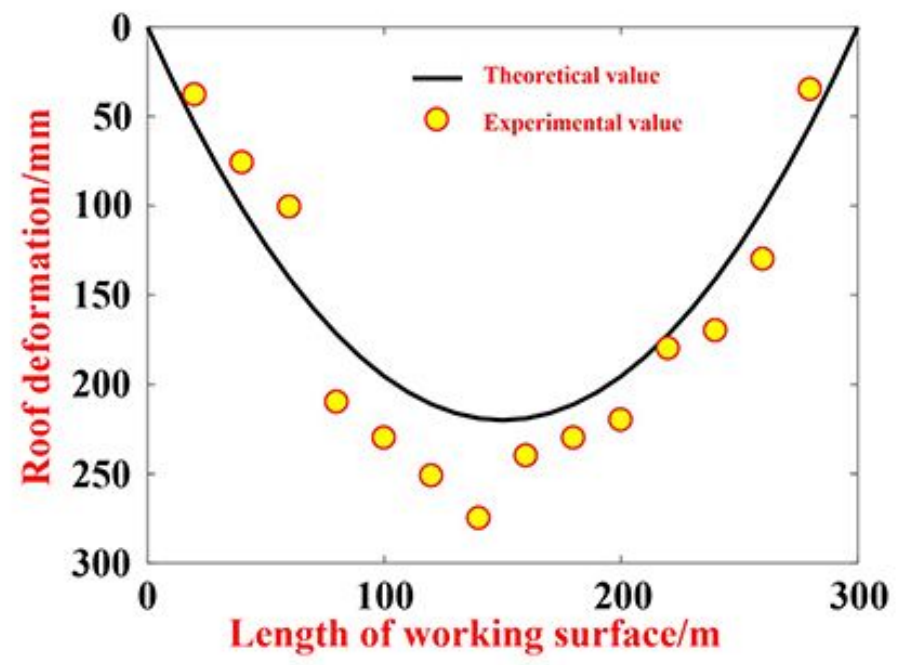

(a) Supporting strength of $1.7 \mathrm{MPa}$

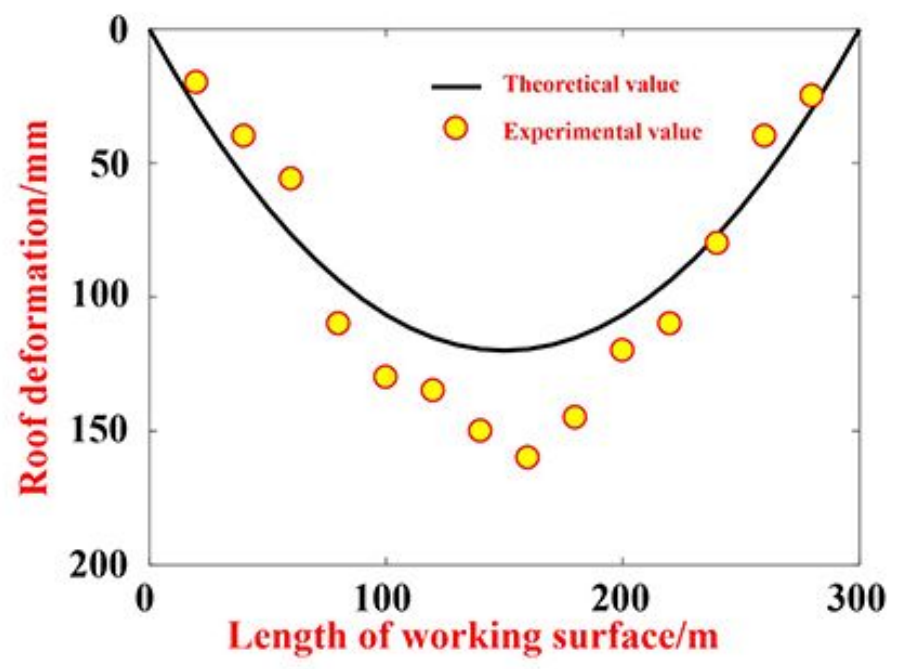

(b)Supporting strength of $2.0 \mathrm{MPa}$

Figure 22

Comparison of theoretical and experimental values of roof deformation in the working face

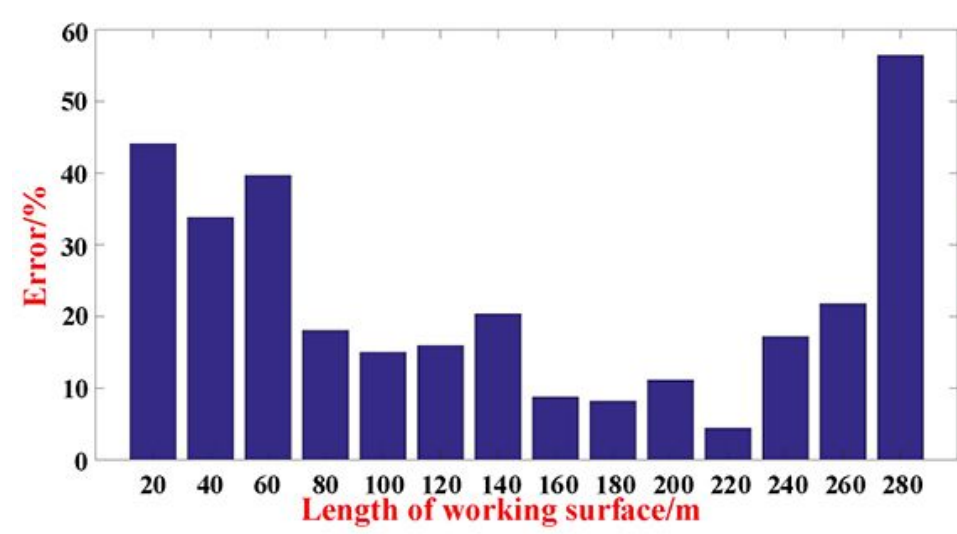

(a) Supporting strength is $1.7 \mathrm{MPa}$

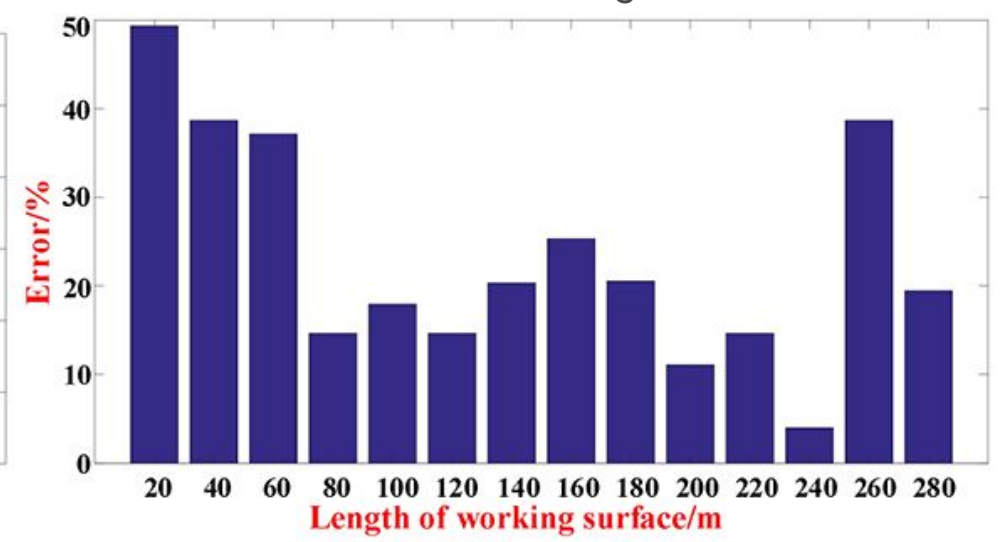

(b)supporting strength is $2.0 \mathrm{MPa}$

Figure 23

Experimental and theoretical error rates for different support strengths 

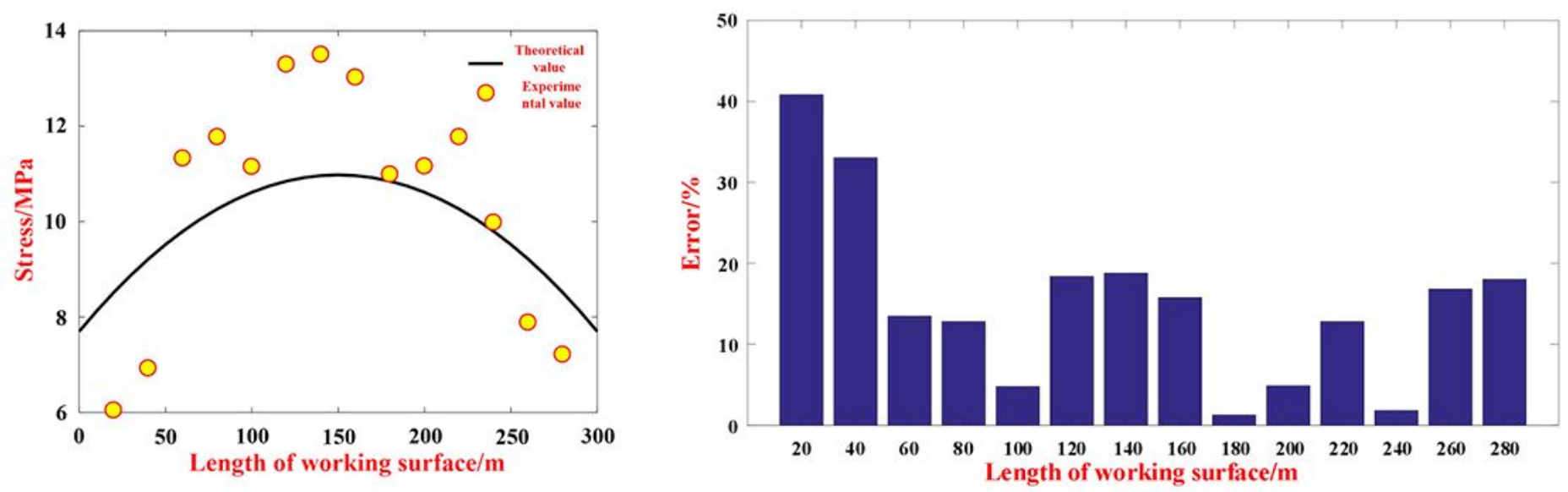

Figure 24

Comparison of the theoretical and experimental values of the stress distribution 